Supporting information for

\title{
Cytotoxic Physalins from Aeroponically Grown Physalis acutifolia
}

Guo-Bo Xu, ${ }^{\dagger}+$ Ya-Ming Xu, ${ }^{\dagger}$ E. M. Kithsiri Wijeratne,${ }^{\dagger}$ Fatemeh Ranjbar, ${ }^{\dagger}$ Manping X. Liu, ${ }^{\dagger}$ and A. A. Leslie Gunatilaka*,†

†Southwest Center for Natural Products Research, School of Natural Resources and the

Environment, College of Agriculture and Life Sciences, University of Arizona, 250 E. Valencia

Road, Tucson, Arizona 85706, United States

State Key Laboratory of Functions and Applications of Medicinal Plants \& School of Pharmacy,

Guizhou Medical University, Guian New District 550025, Guizhou, P. R. China 


\section{Table of Contents}

Figure S1 ${ }^{1} \mathrm{H}$ NMR spectrum (400 MHz) of $\mathbf{1}$ in $\mathrm{CDCl}_{3}$ ${ }^{13} \mathrm{C}$ NMR spectrum $(100 \mathrm{MHz})$ of $\mathbf{1}$ in $\mathrm{CDCl}_{3}$

Figure S8

${ }^{13} \mathrm{C}$ NMR spectrum $(100 \mathrm{MHz})$ of 2 in $\mathrm{CDCl}_{3}$

Figure S9 DEPT spectrum $(100 \mathrm{MHz})$ of $\mathbf{2}$ in $\mathrm{CDCl}_{3}$

Figure S10 HSQC spectrum $(400 \mathrm{MHz})$ of $\mathbf{2}$ in $\mathrm{CDCl}_{3}$

Figure S11 $\mathrm{HMBC}$ spectrum $(400 \mathrm{MHz})$ of $\mathbf{2}$ in $\mathrm{CDCl}_{3}$

Figure S12 ${ }^{1} \mathrm{H}$ NMR spectrum (400 MHz) of $\mathbf{3}$ in acetone- $d_{6}$

Figure S14 DEPT spectrum (100 MHz) of $\mathbf{3}$ in acetone- $d_{6}$ 


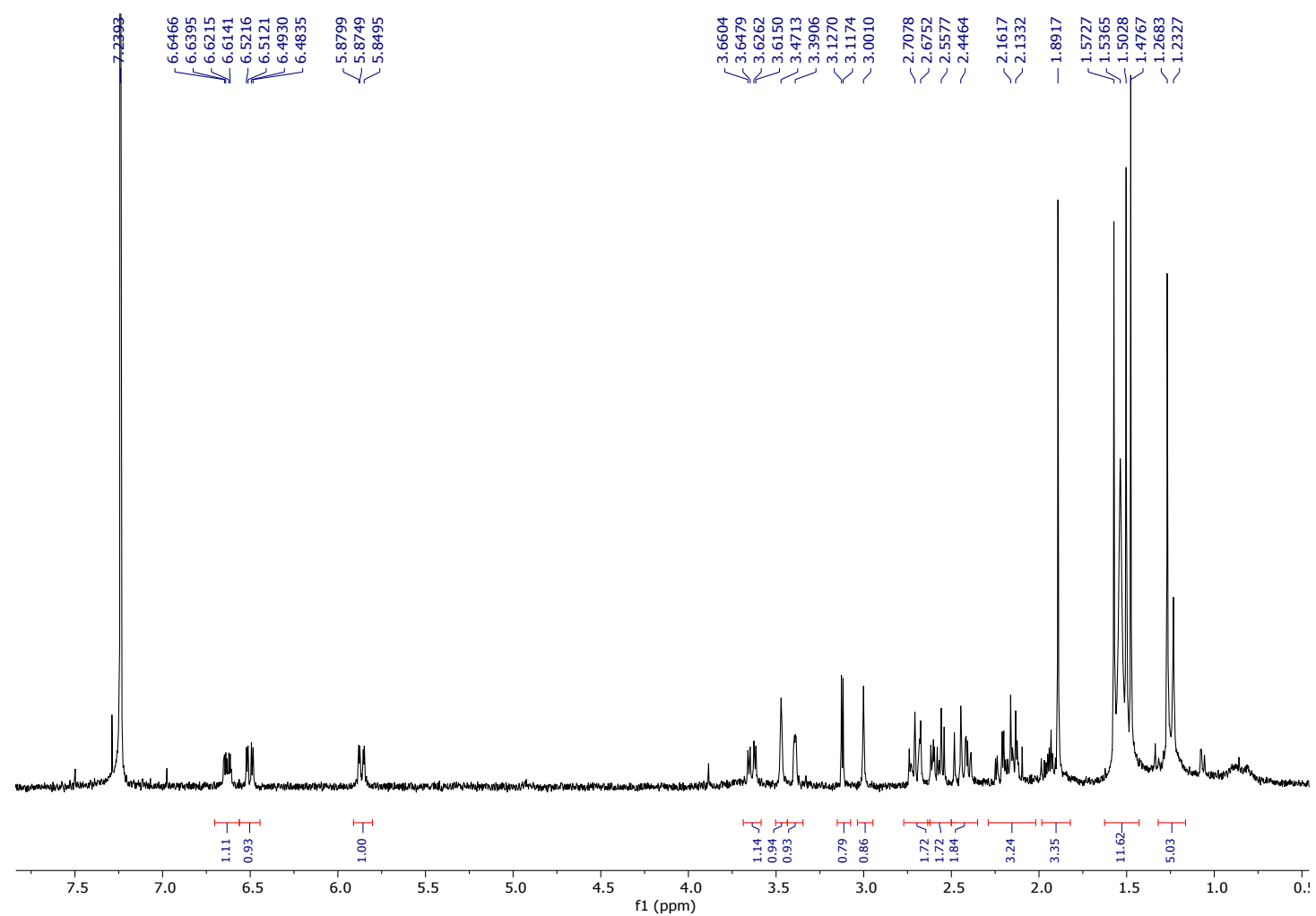

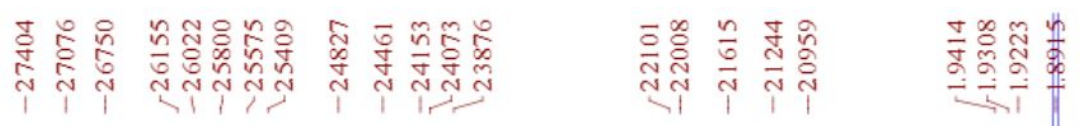

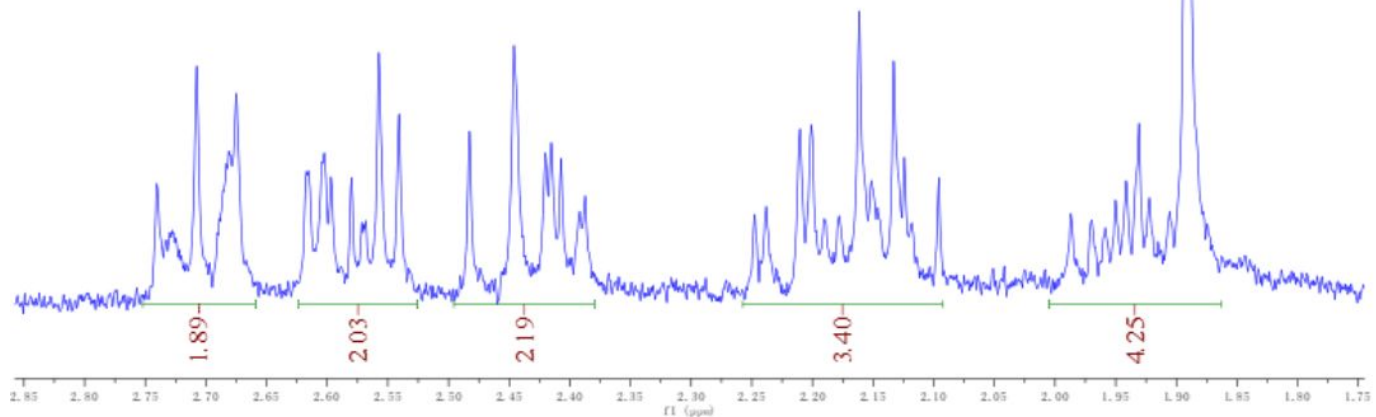

Figure S1. ${ }^{1} \mathrm{H}$ NMR spectrum $(400 \mathrm{MHz})$ of 1 in $\mathrm{CDCl}_{3}$ 


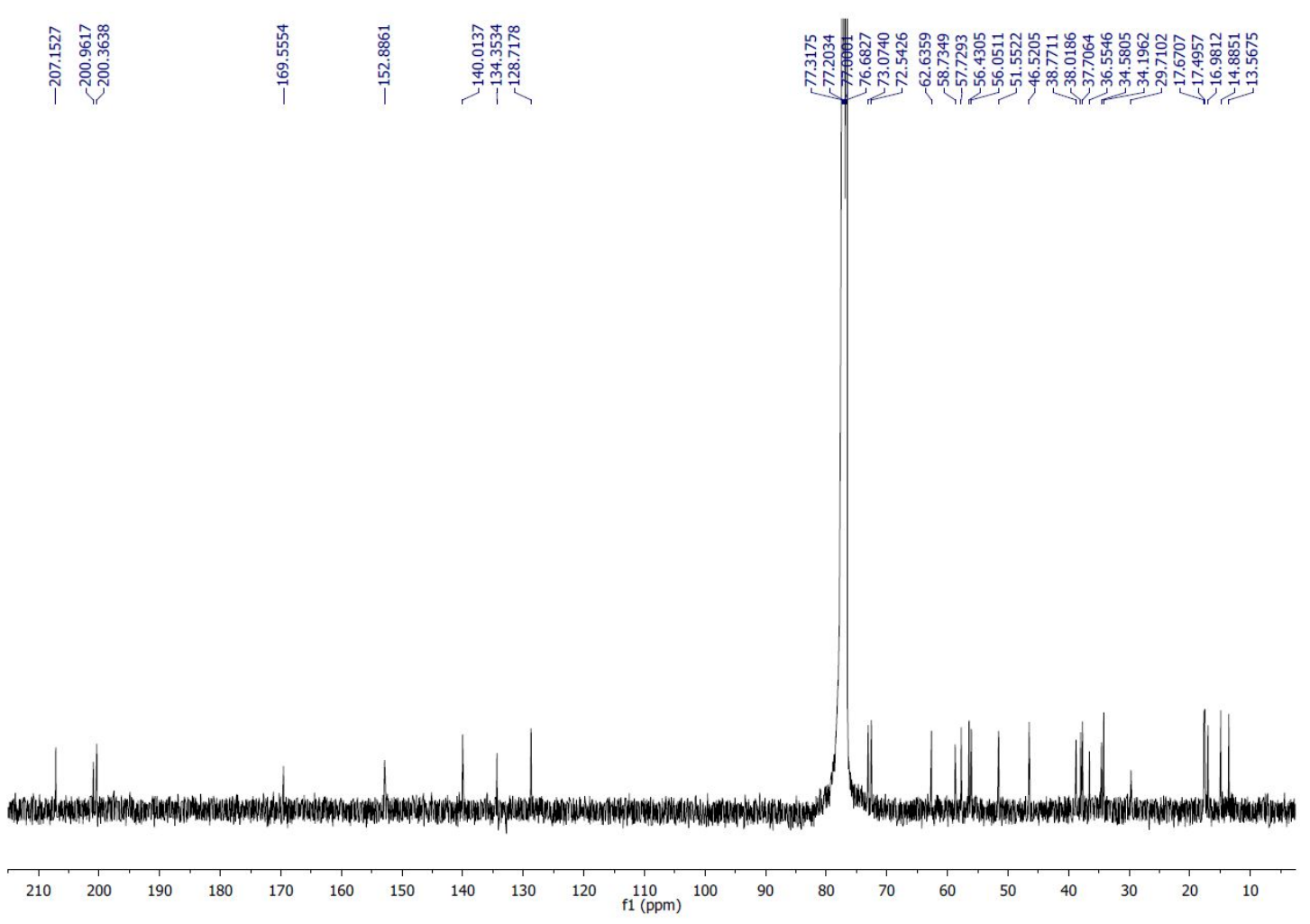

Figure S2. ${ }^{13} \mathrm{C}$ NMR spectrum $(100 \mathrm{MHz})$ of $\mathbf{1}$ in $\mathrm{CDCl}_{3}$ 

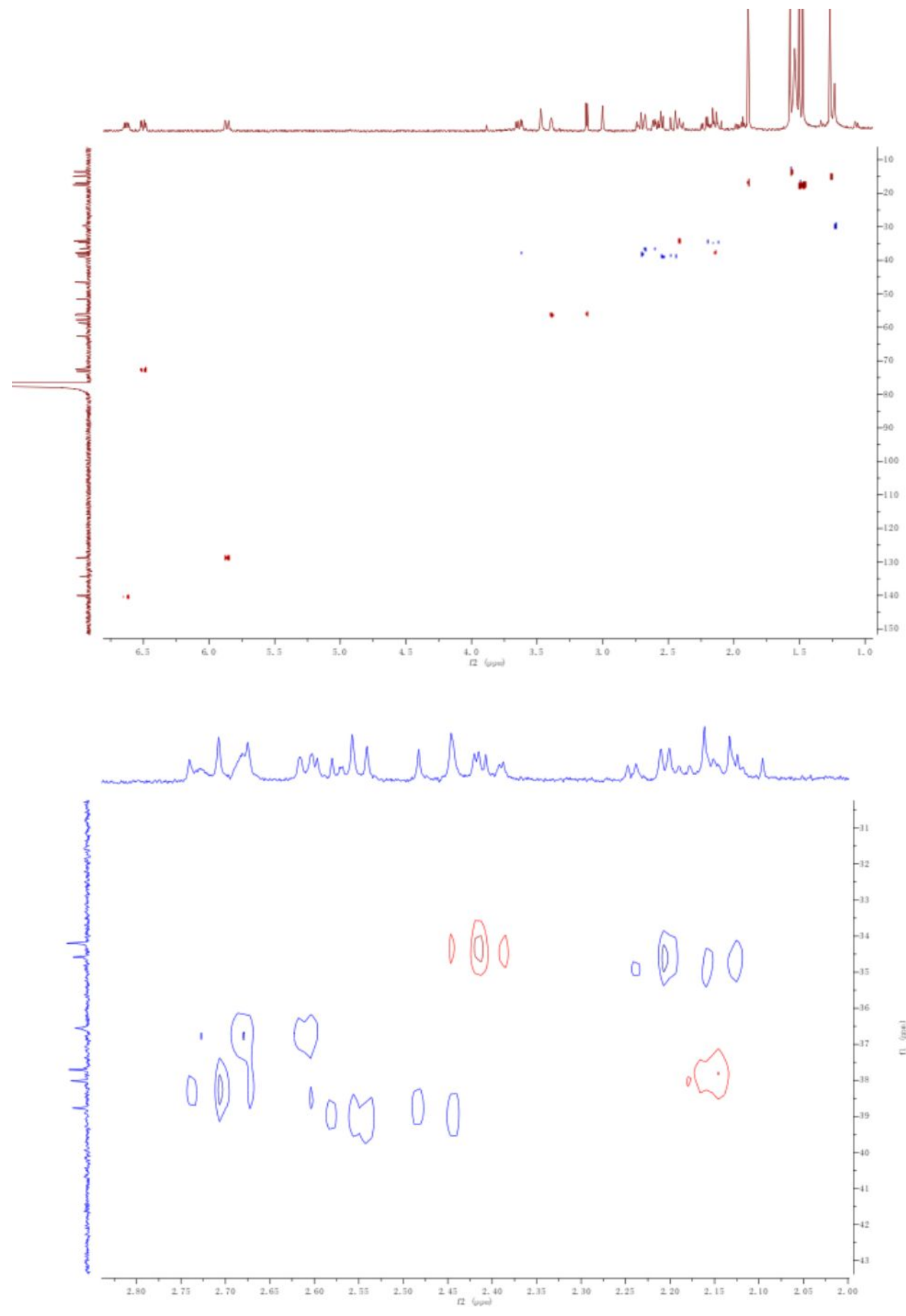

Figure S3. HSQC spectrum (400 MHz) of 1 in $\mathrm{CDCl}_{3}$ 


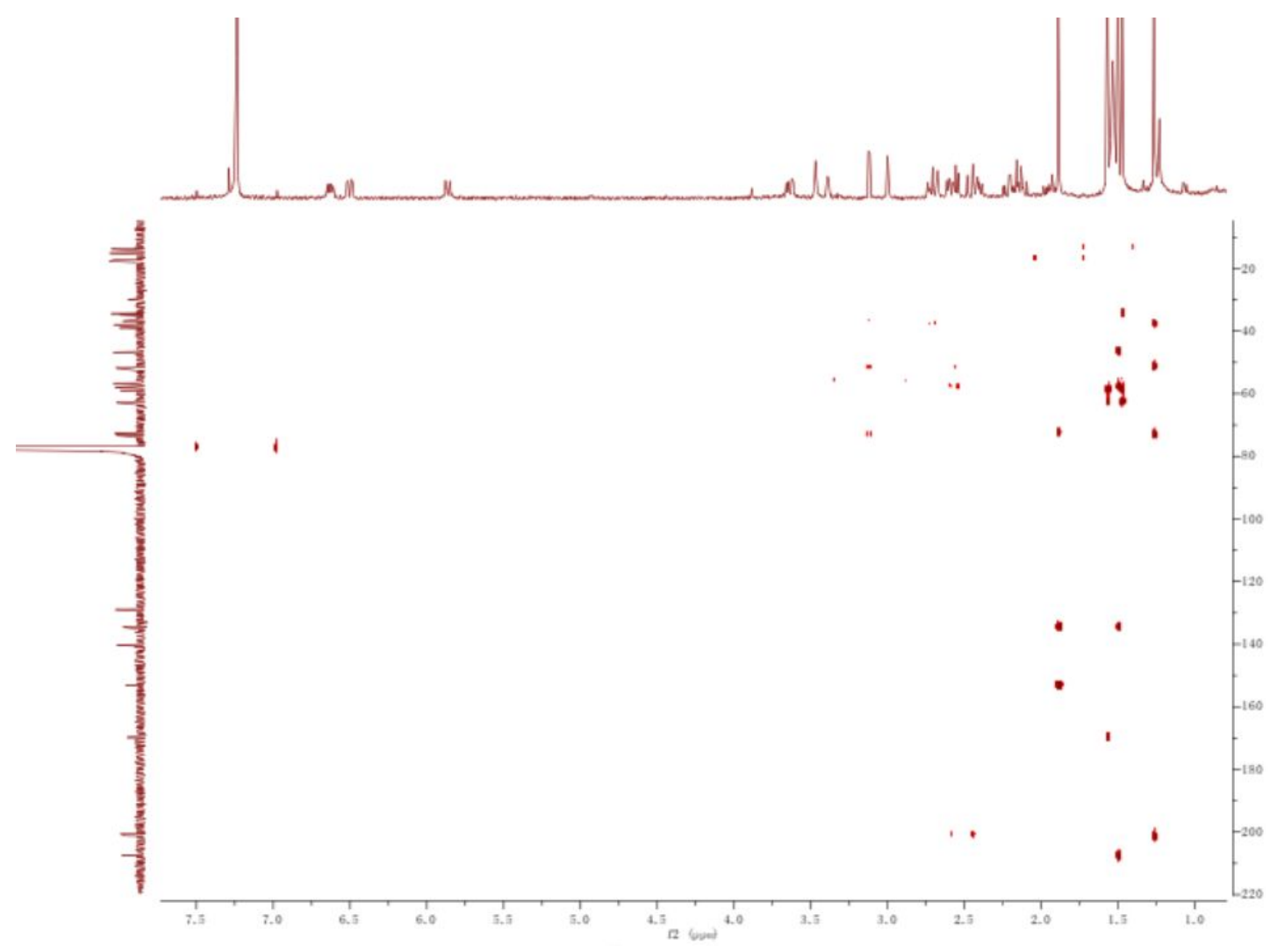

Figure S4. $\mathrm{HMBC}$ spectrum $(400 \mathrm{MHz})$ of 1 in $\mathrm{CDCl}_{3}$

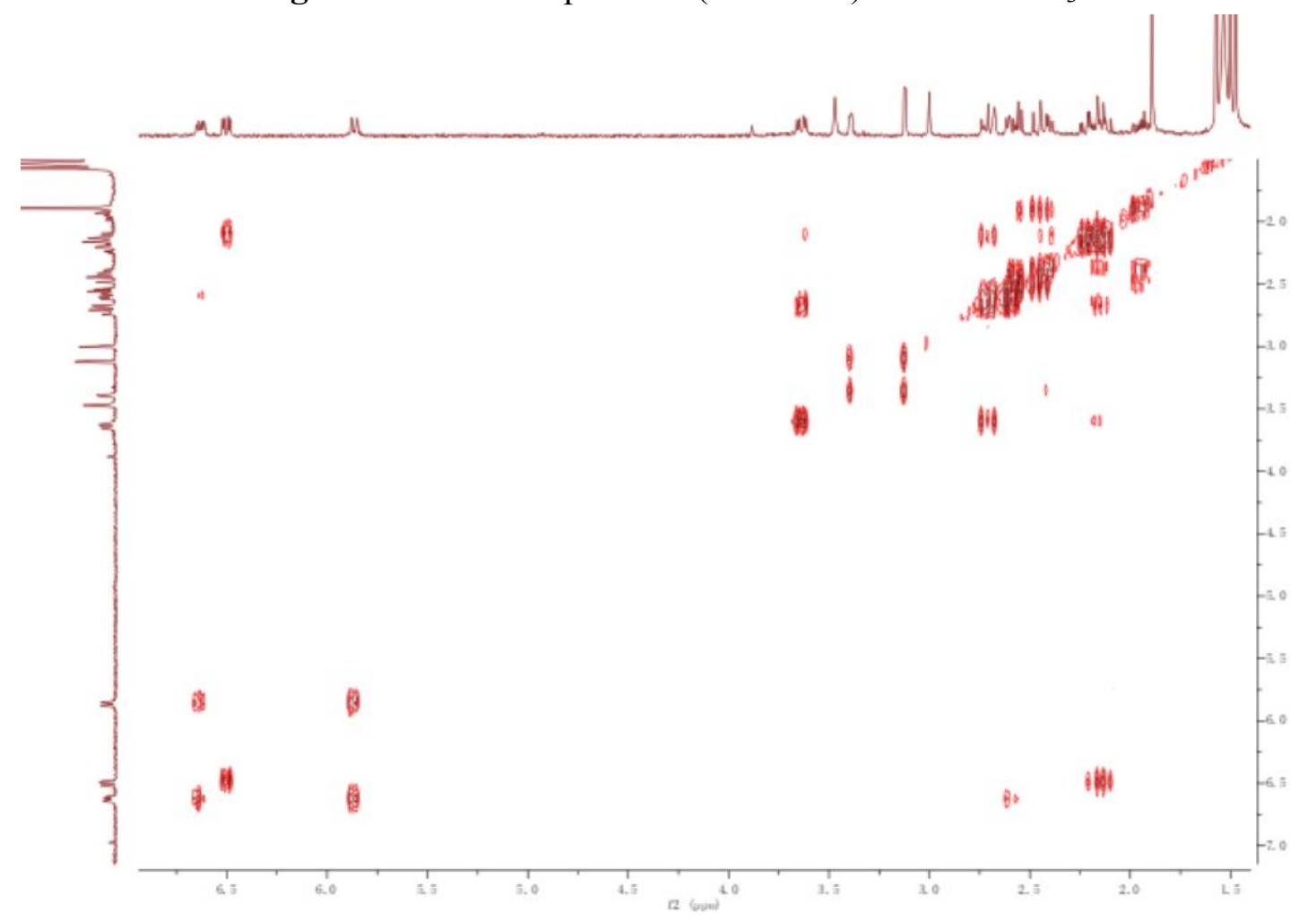

Figure S5. ${ }^{1} \mathrm{H}-{ }^{1} \mathrm{H}$ COSY spectrum $(400 \mathrm{MHz})$ of 1 in $\mathrm{CDCl}_{3}$ 


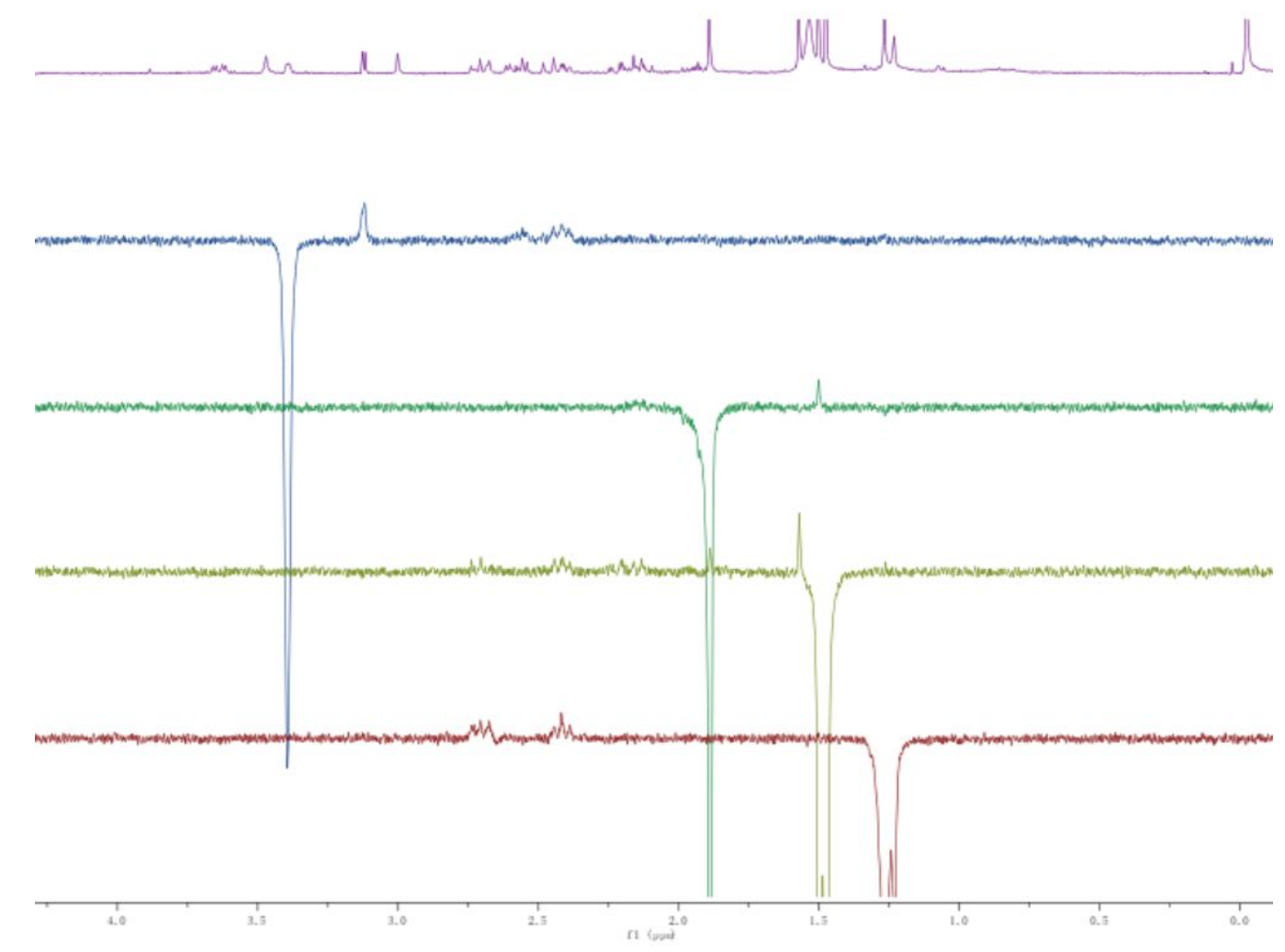

Figure S6. 1D NOESY spectrum (400 MHz) of 1 in $\mathrm{CDCl}_{3}$

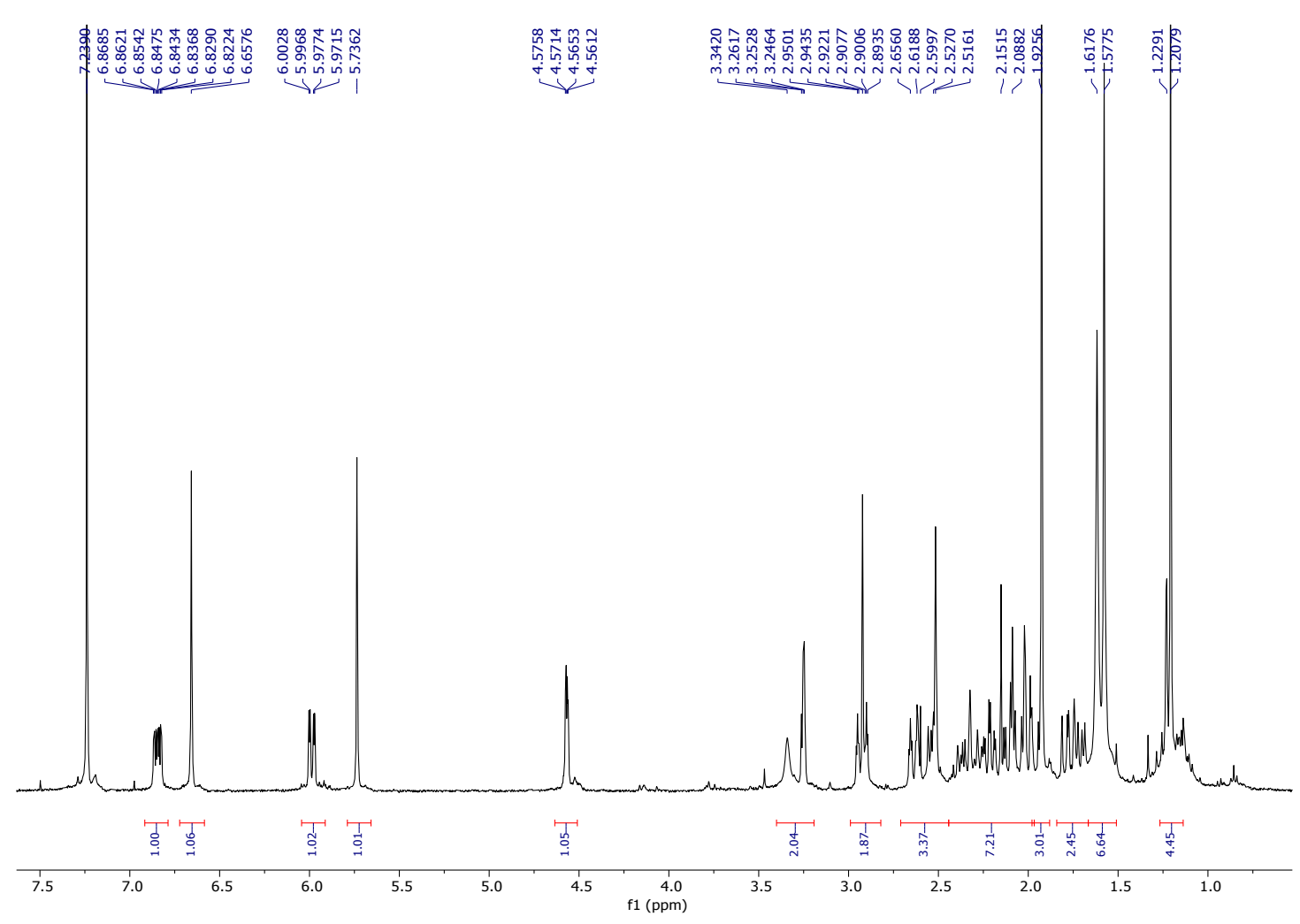

Figure S7. ${ }^{1} \mathrm{H}$ NMR spectrum $(400 \mathrm{MHz})$ of 2 in $\mathrm{CDCl}_{3}$ 


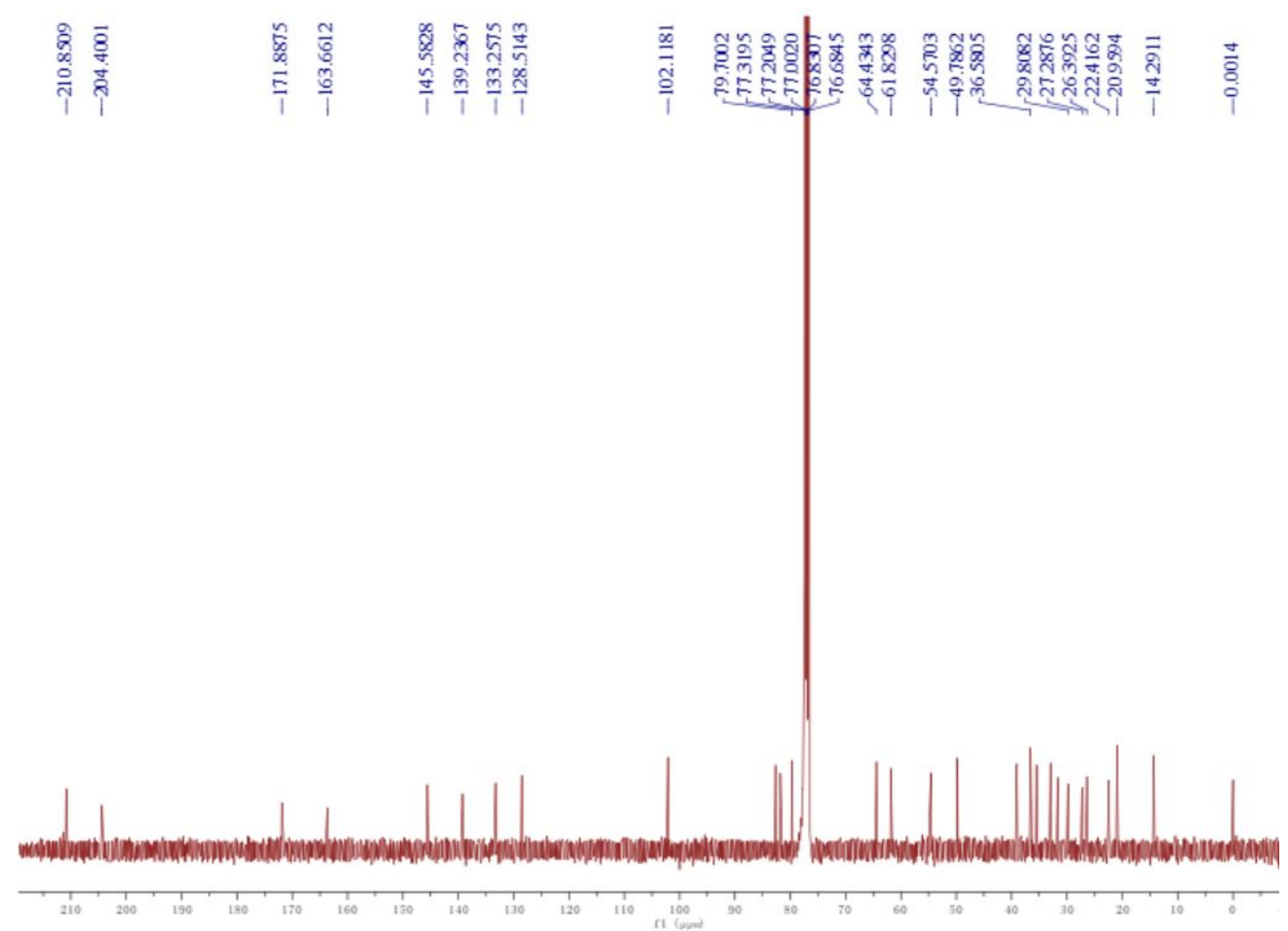

Figure S8. ${ }^{13} \mathrm{C}$ NMR spectrum $(100 \mathrm{MHz})$ of 2 in $\mathrm{CDCl}_{3}$

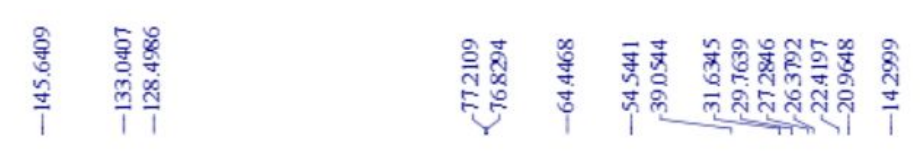
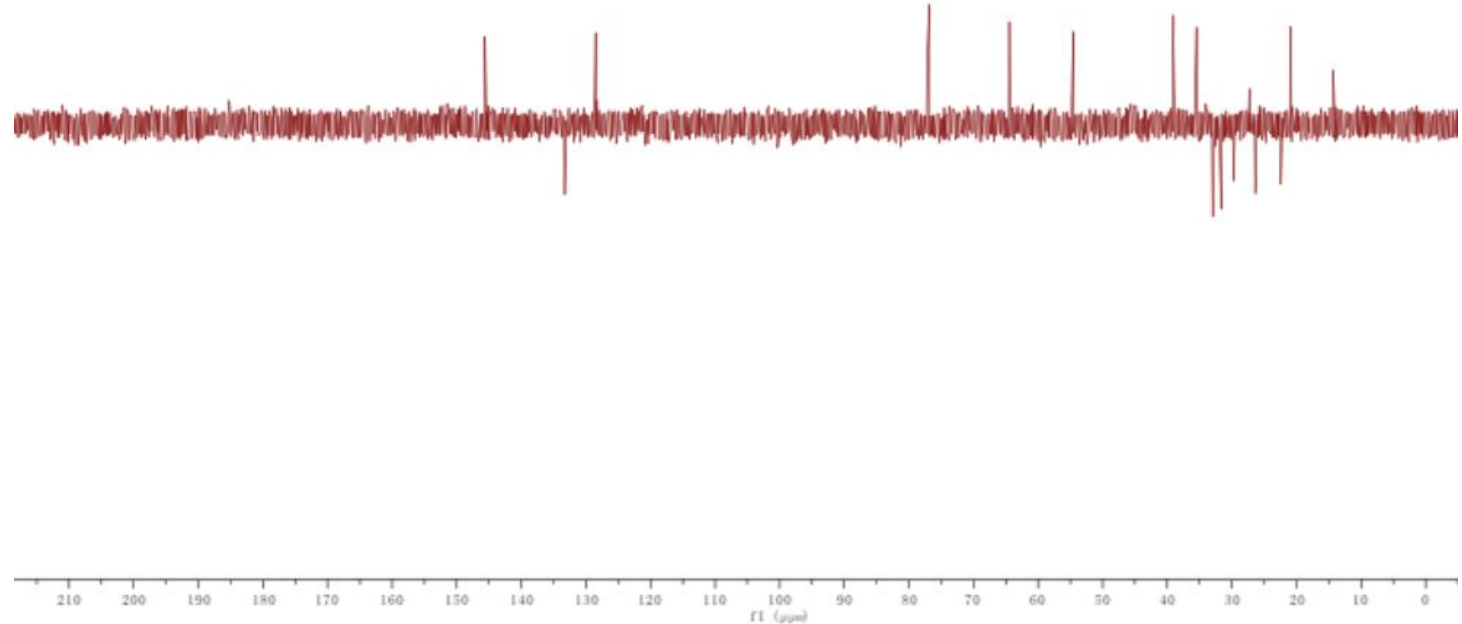

Figure S9. DEPT spectrum $(100 \mathrm{MHz})$ of 2 in $\mathrm{CDCl}_{3}$ 


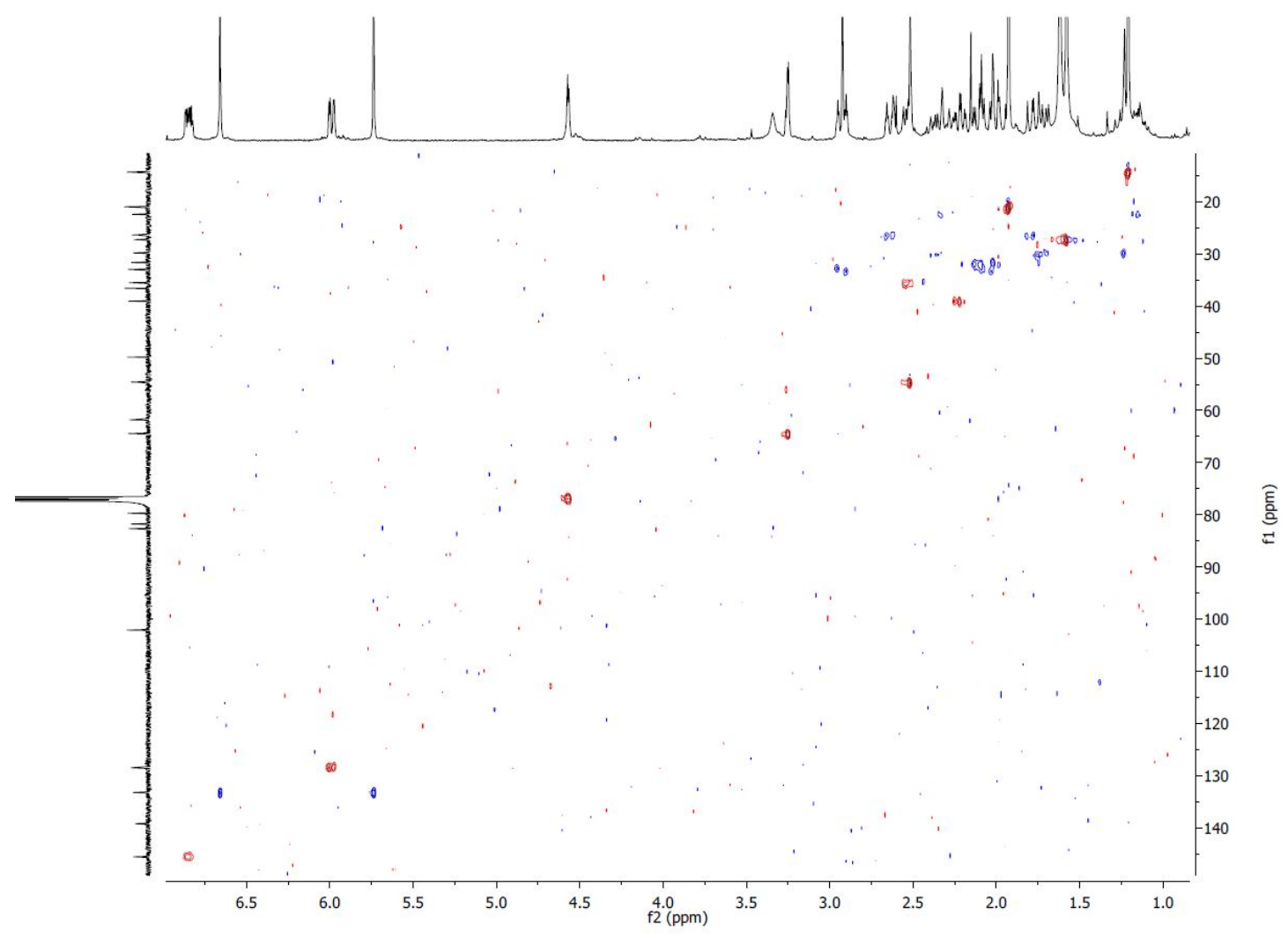

Figure S10. HSQC spectrum (400 MHz) of 2 in $\mathrm{CDCl}_{3}$

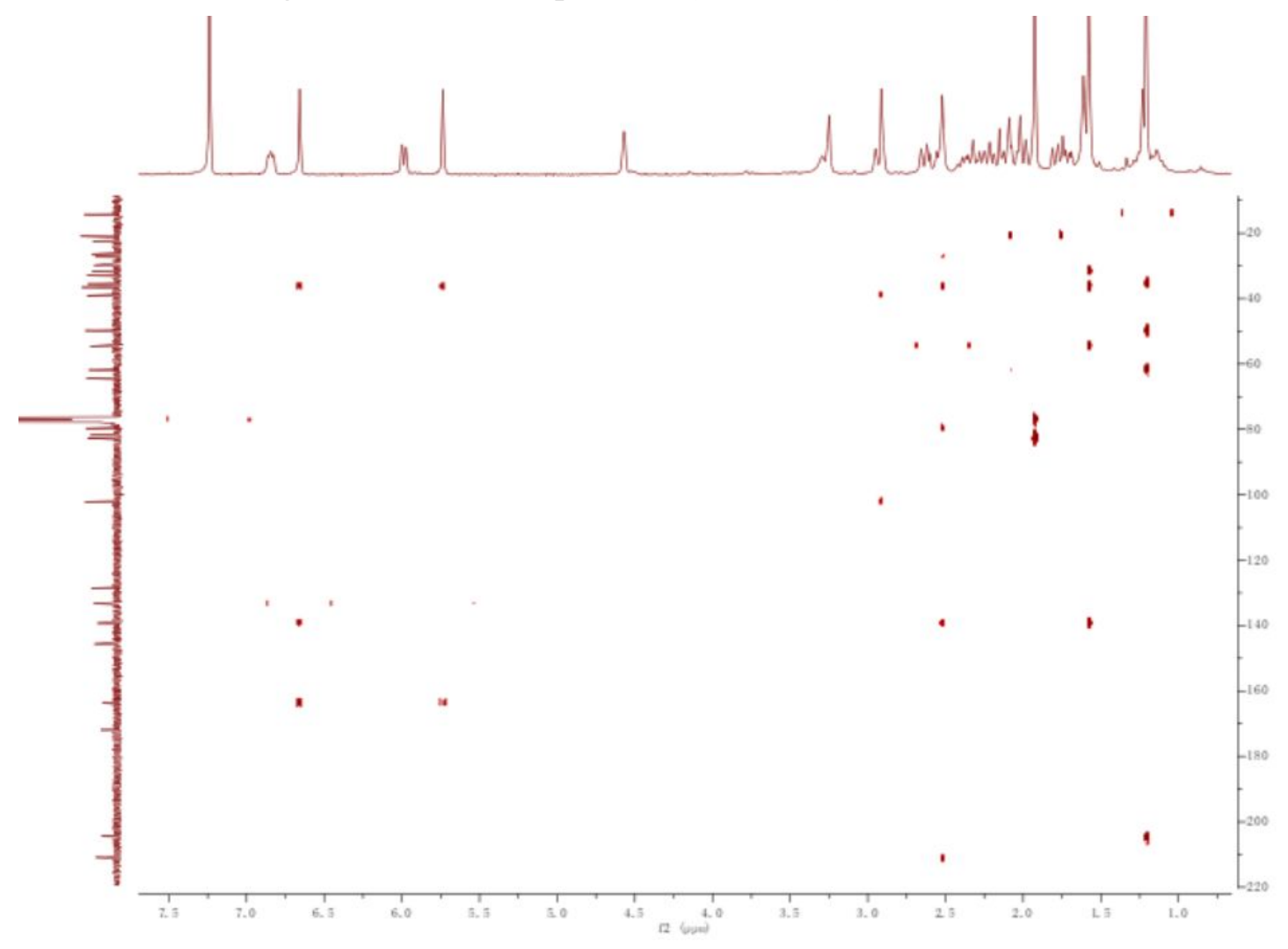

Figure S11. HMBC spectrum (400 MHz) of 2 in $\mathrm{CDCl}_{3}$ 


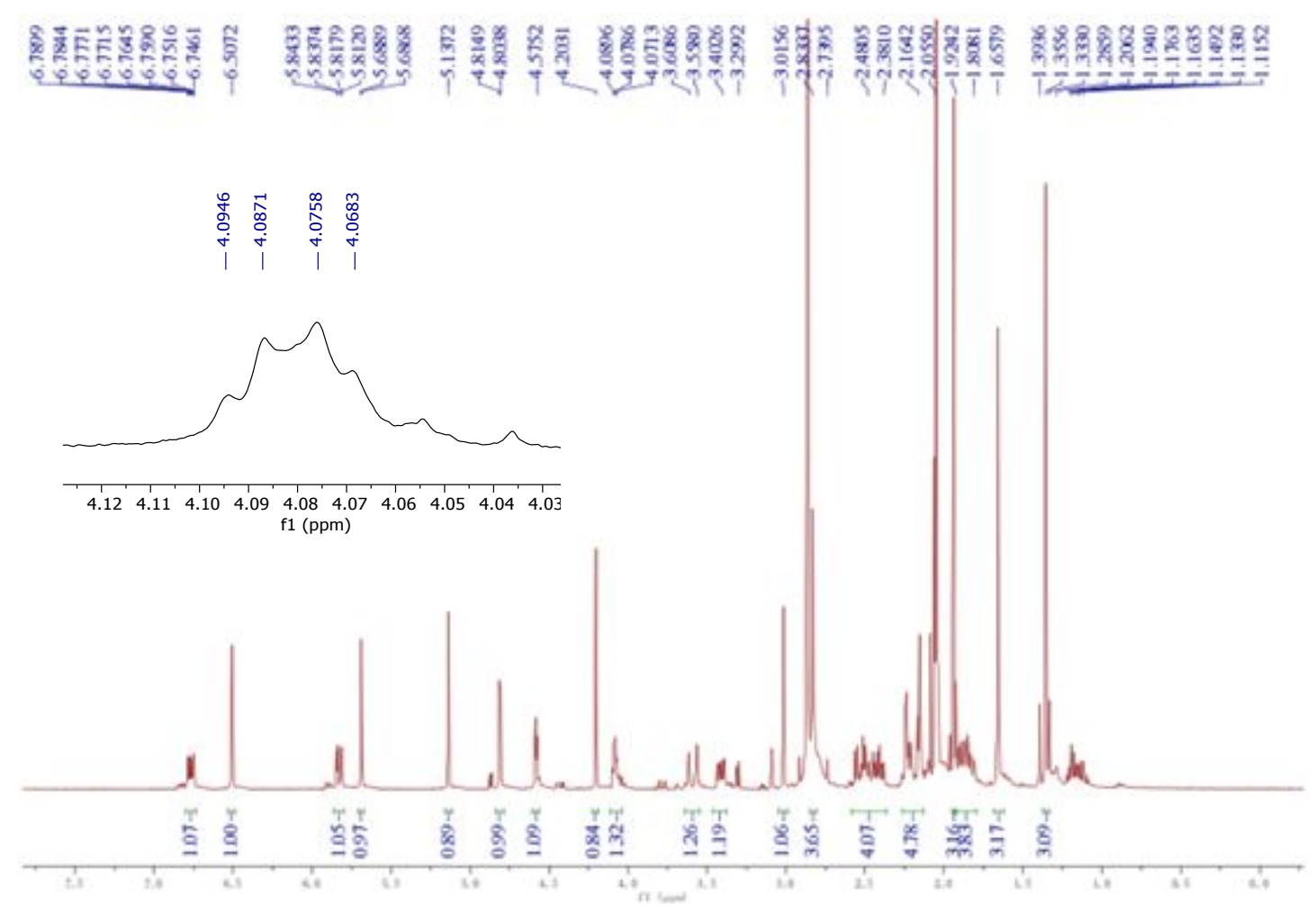

Figure S12. ${ }^{1} \mathrm{H}$ NMR spectrum $(400 \mathrm{MHz})$ of 3 in acetone- $d_{6}$

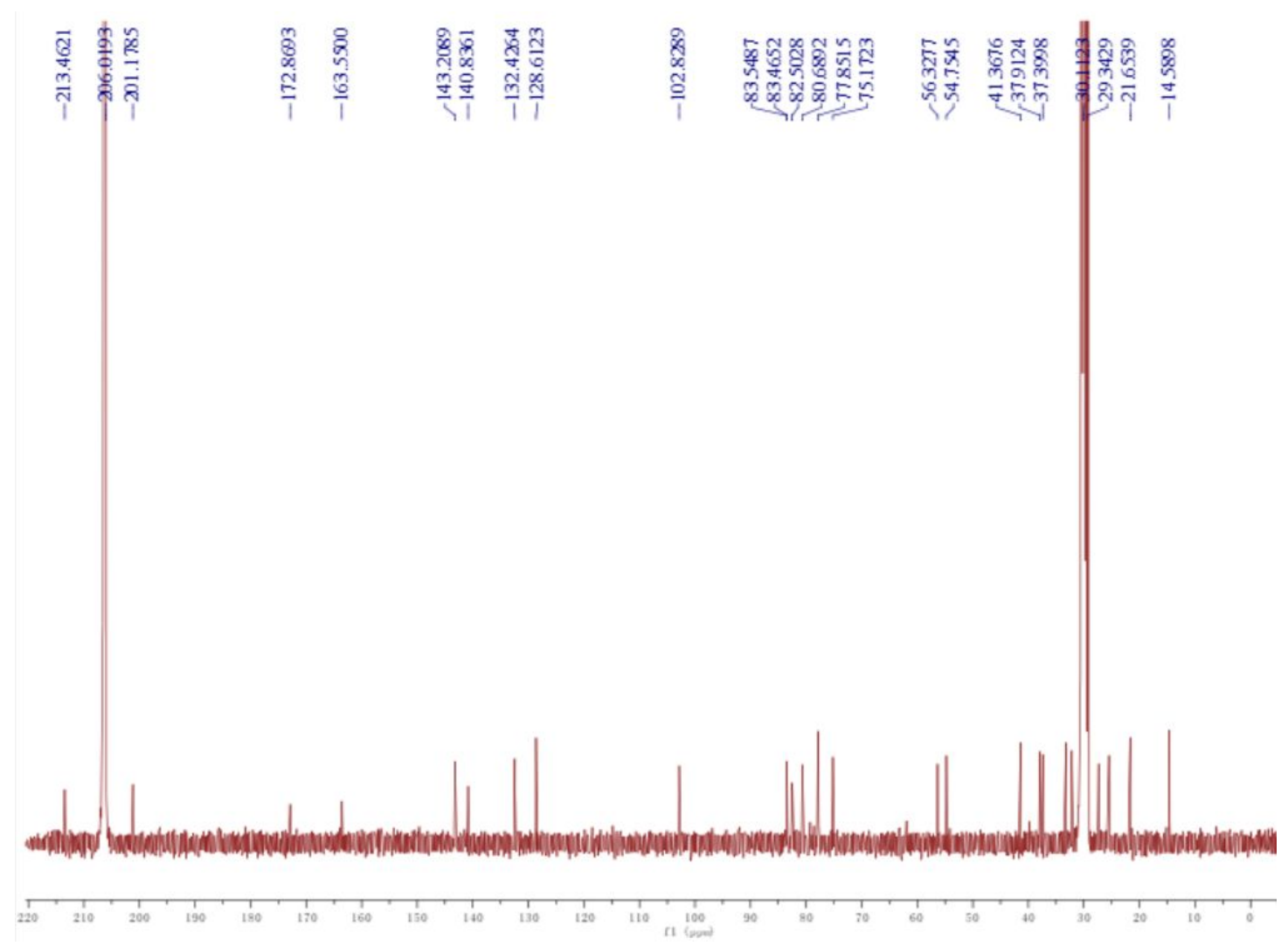

Figure S13. ${ }^{13} \mathrm{H}$ NMR spectrum $(100 \mathrm{MHz})$ of 3 in acetone- $d_{6}$ 



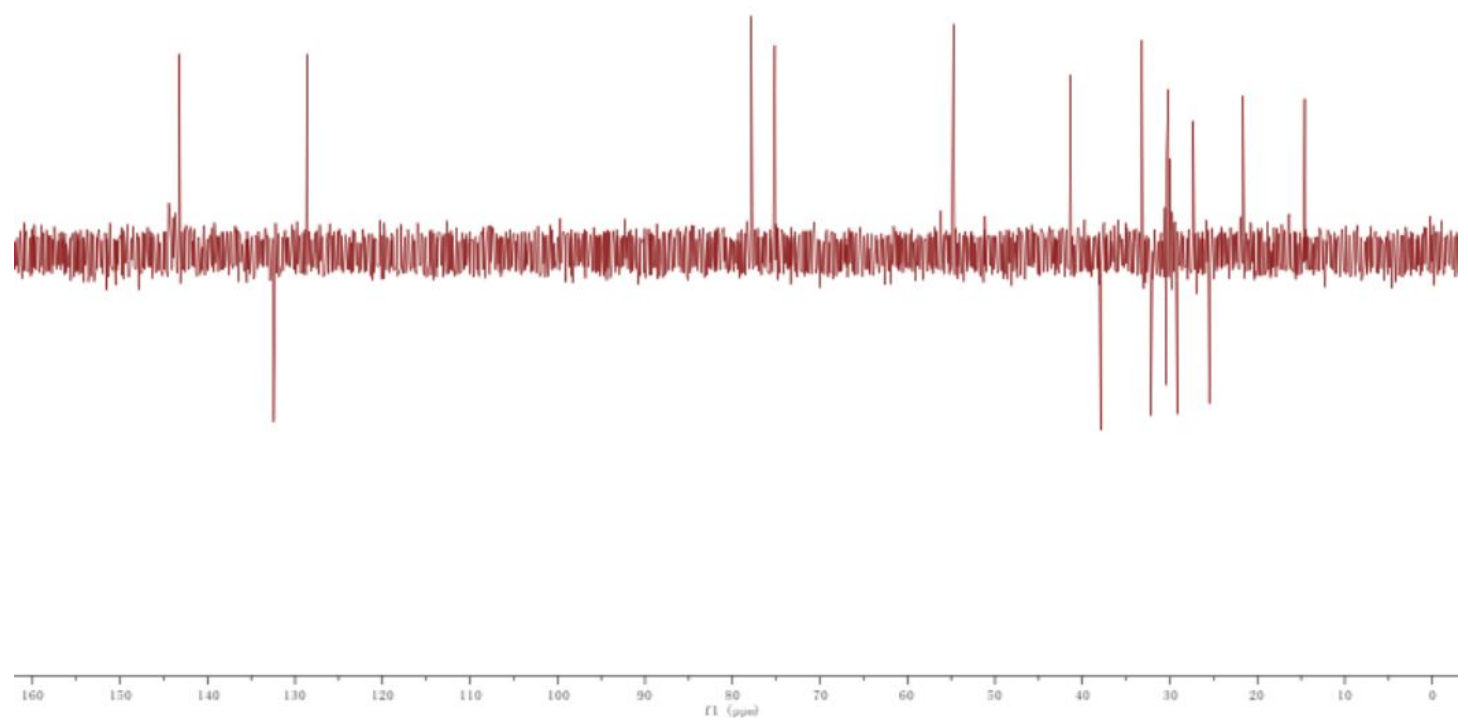

Figure S14. DEPT spectrum $(100 \mathrm{MHz})$ of $\mathbf{3}$ in acetone- $d_{6}$

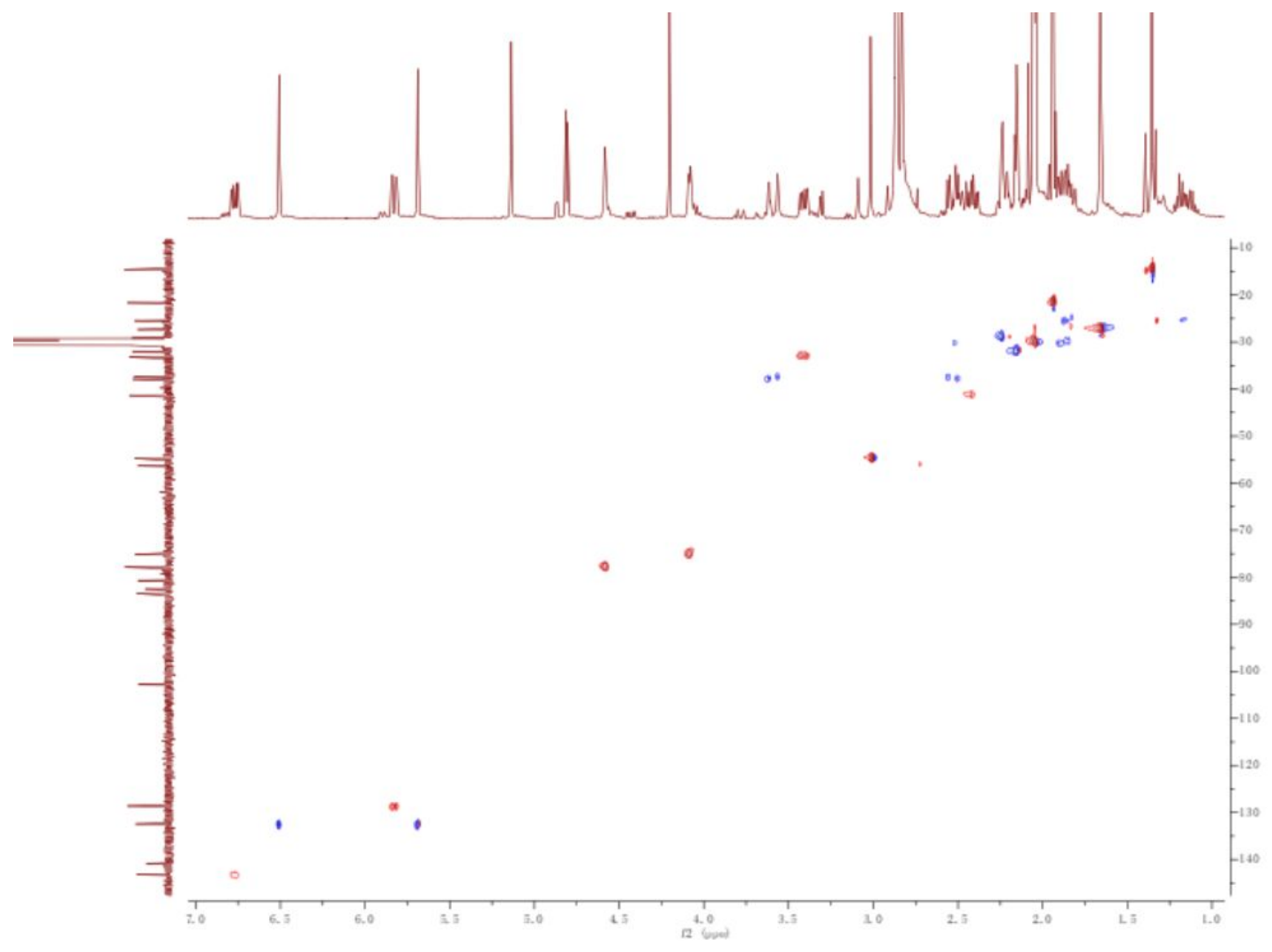

Figure S15. HSQC spectrum $(400 \mathrm{MHz})$ of 3 in acetone- $d_{6}$ 


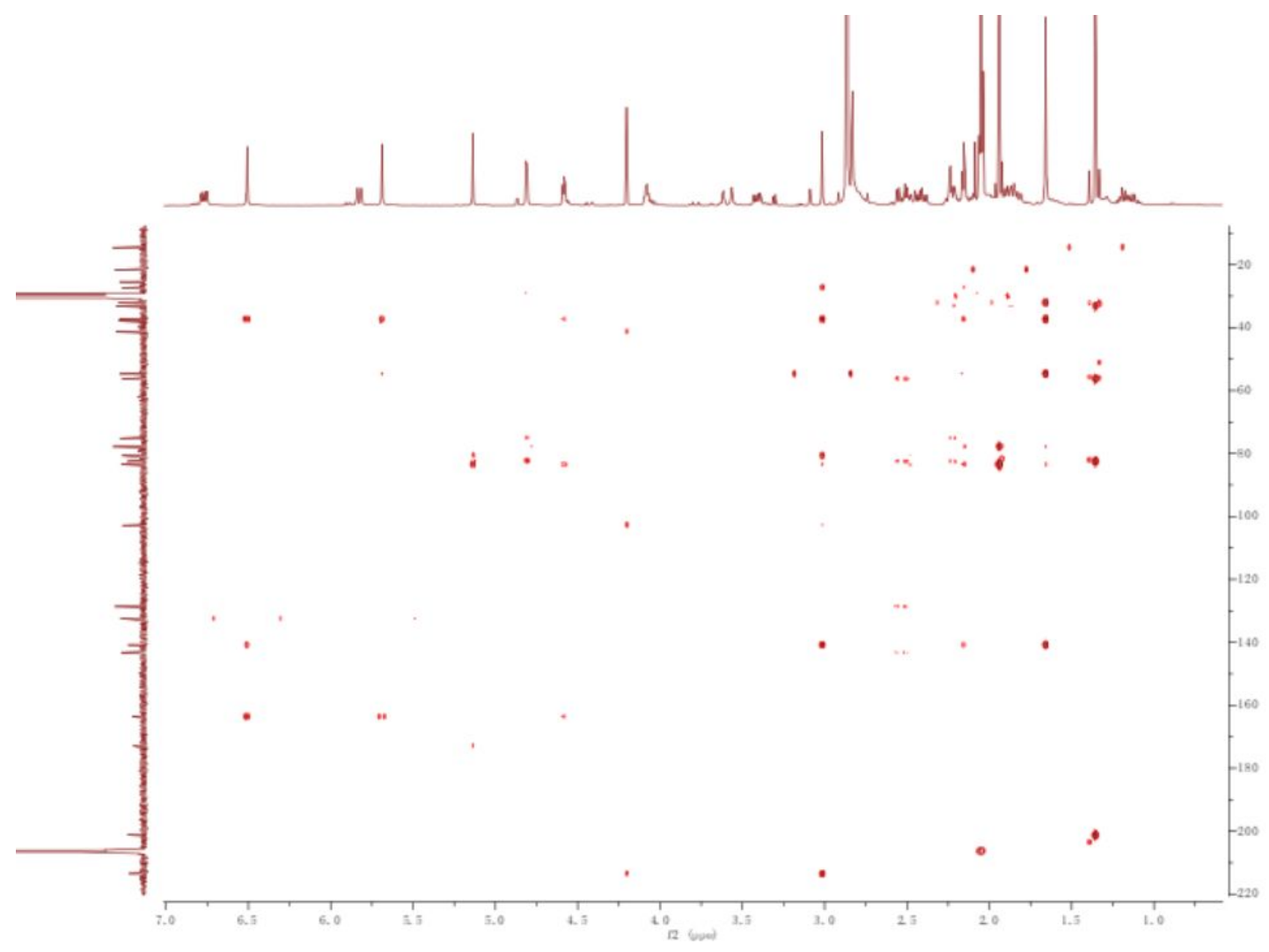

Figure S16. HMBC spectrum $(400 \mathrm{MHz})$ of 3 in acetone- $d_{6}$

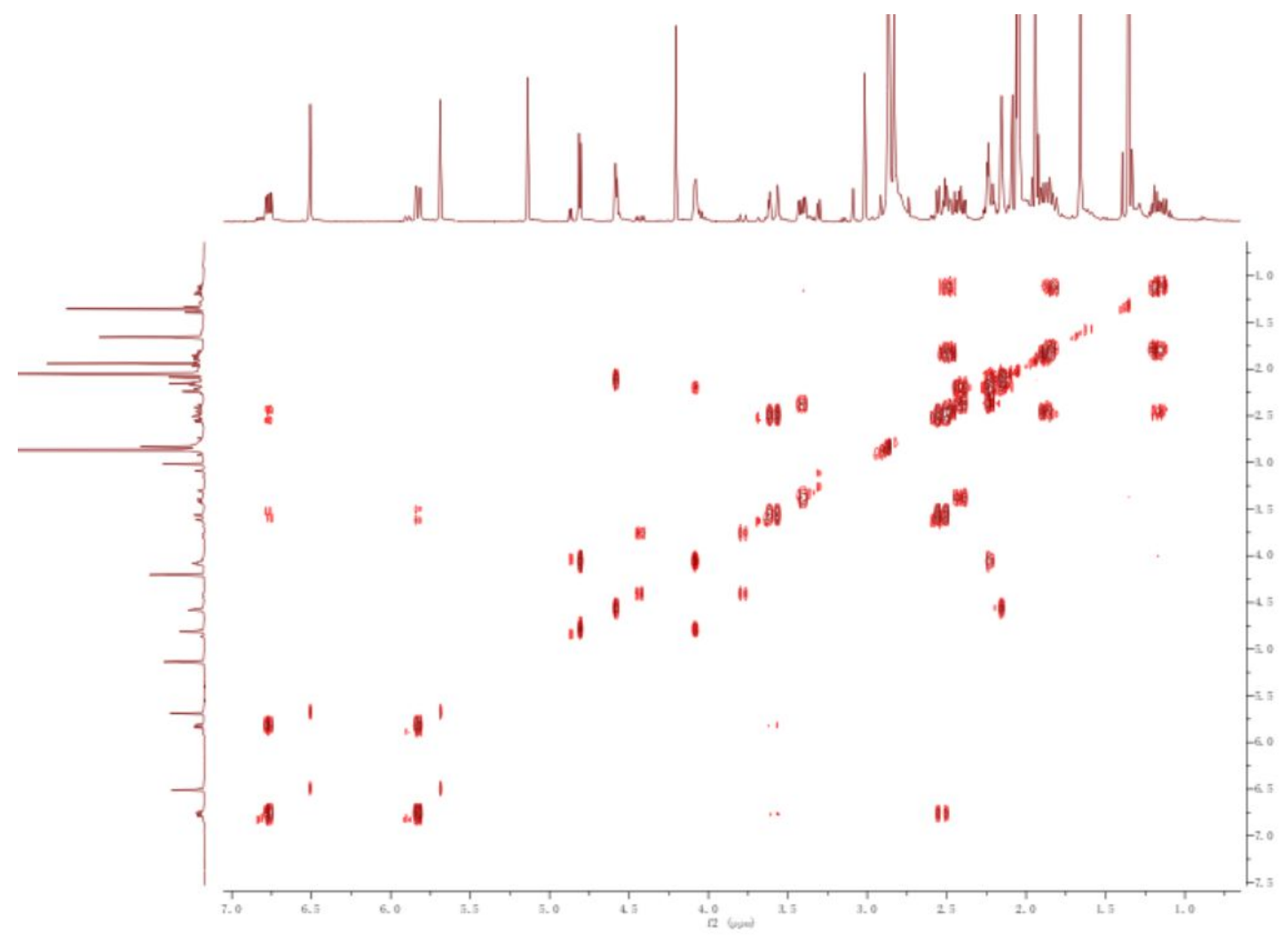

Figure S17. ${ }^{1} \mathrm{H}-1 \mathrm{H}$ COSY spectrum $(400 \mathrm{MHz})$ of $\mathbf{3}$ in acetone- $d_{6}$ 


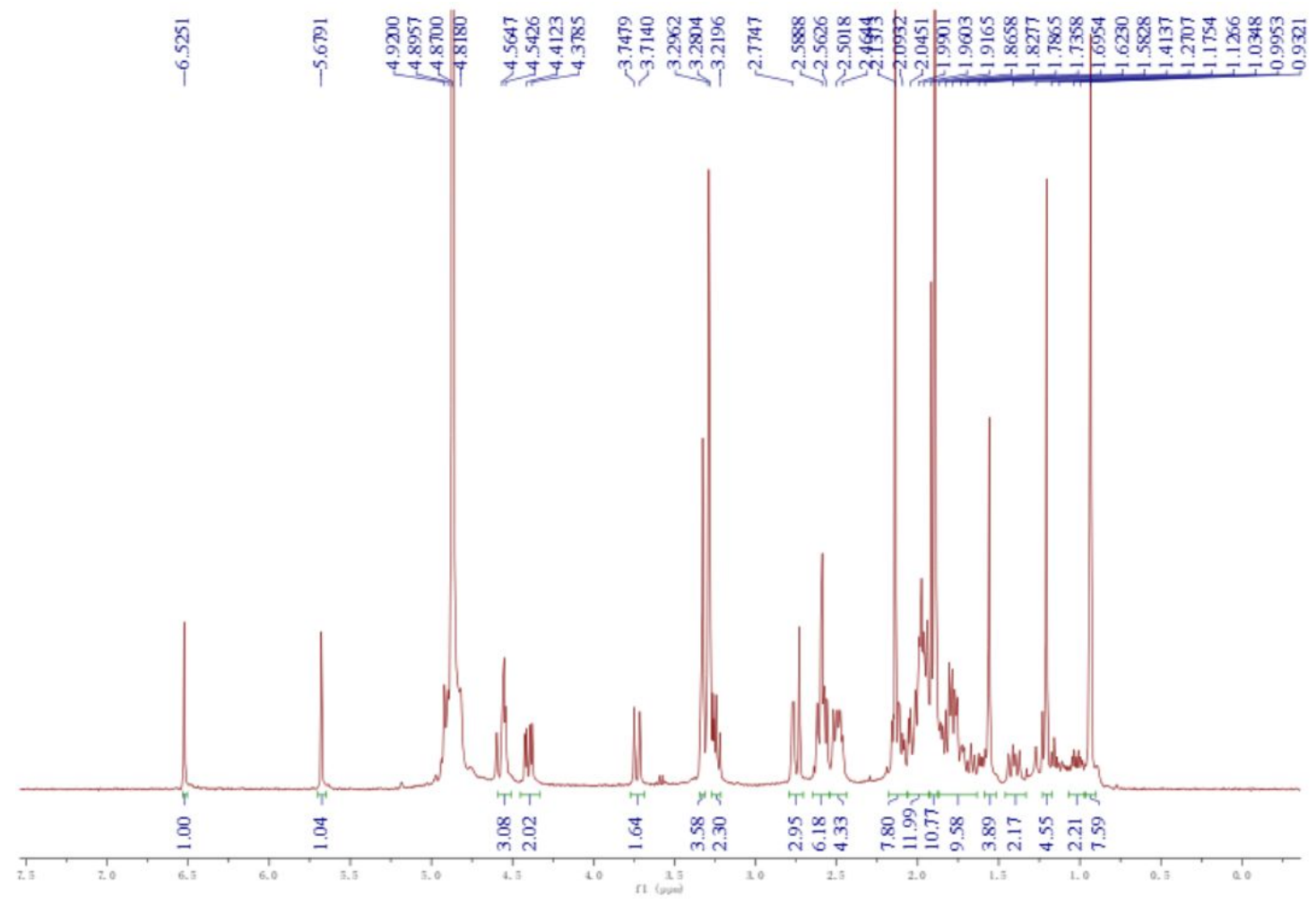

Figure S18. ${ }^{1} \mathrm{H}$ NMR spectrum $(400 \mathrm{MHz})$ of $\mathbf{4 + 5}$ in $\mathrm{CD}_{3} \mathrm{OD}$

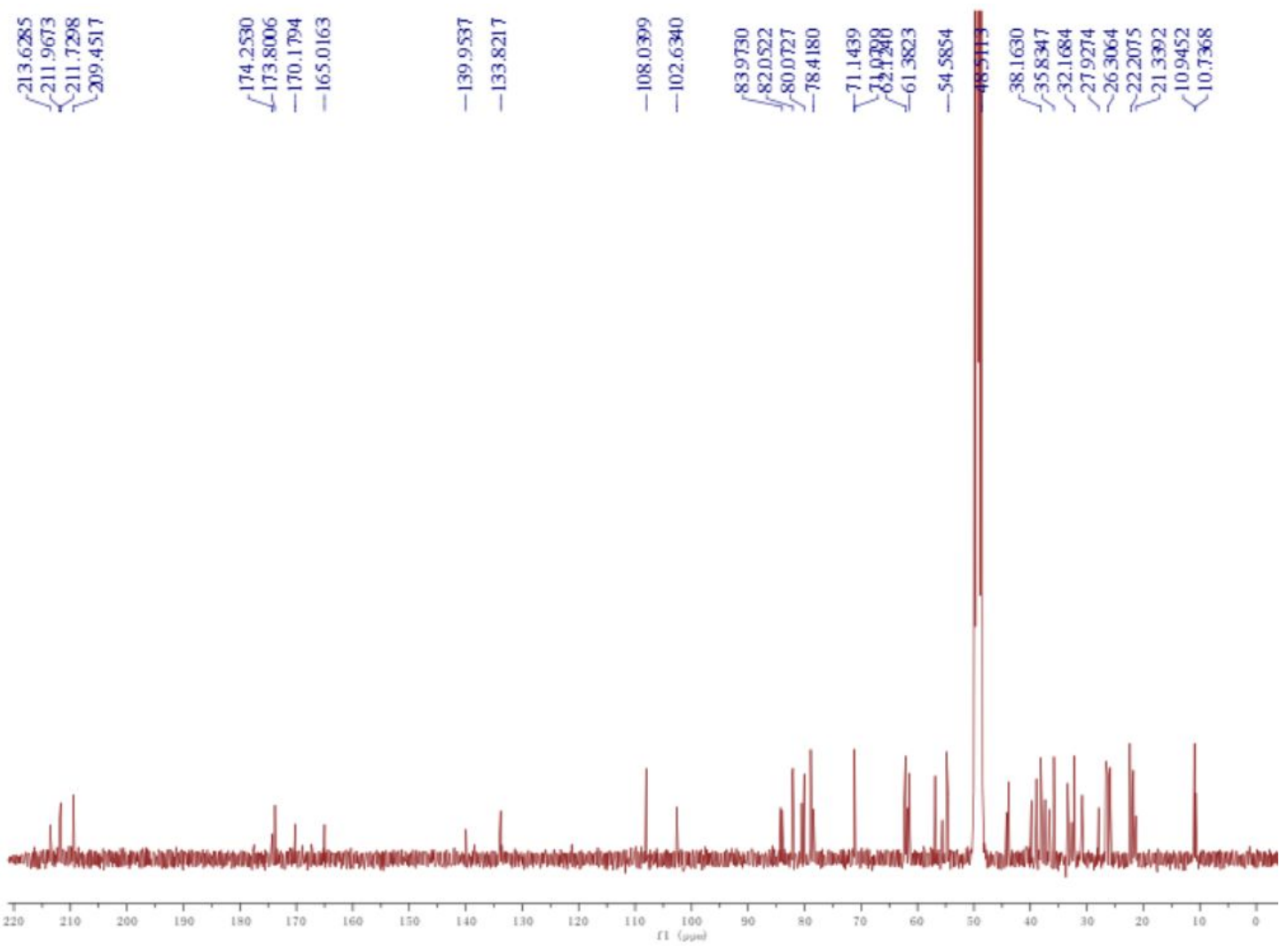

Figure S19. ${ }^{13} \mathrm{C}$ NMR $(100 \mathrm{MHz})$ of $\mathbf{4 + 5}$ in $\mathrm{CD}_{3} \mathrm{OD}$ 


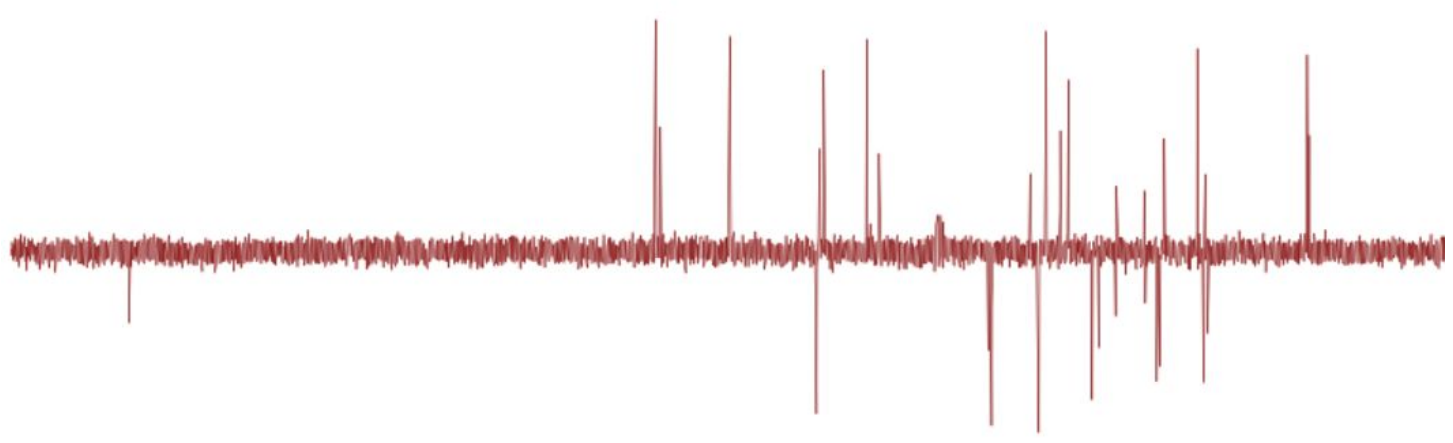

Figure S20. DEPT spectrum $(100 \mathrm{MHz})$ of $\mathbf{4 + 5}$ in $\mathrm{CD}_{3} \mathrm{OD}$

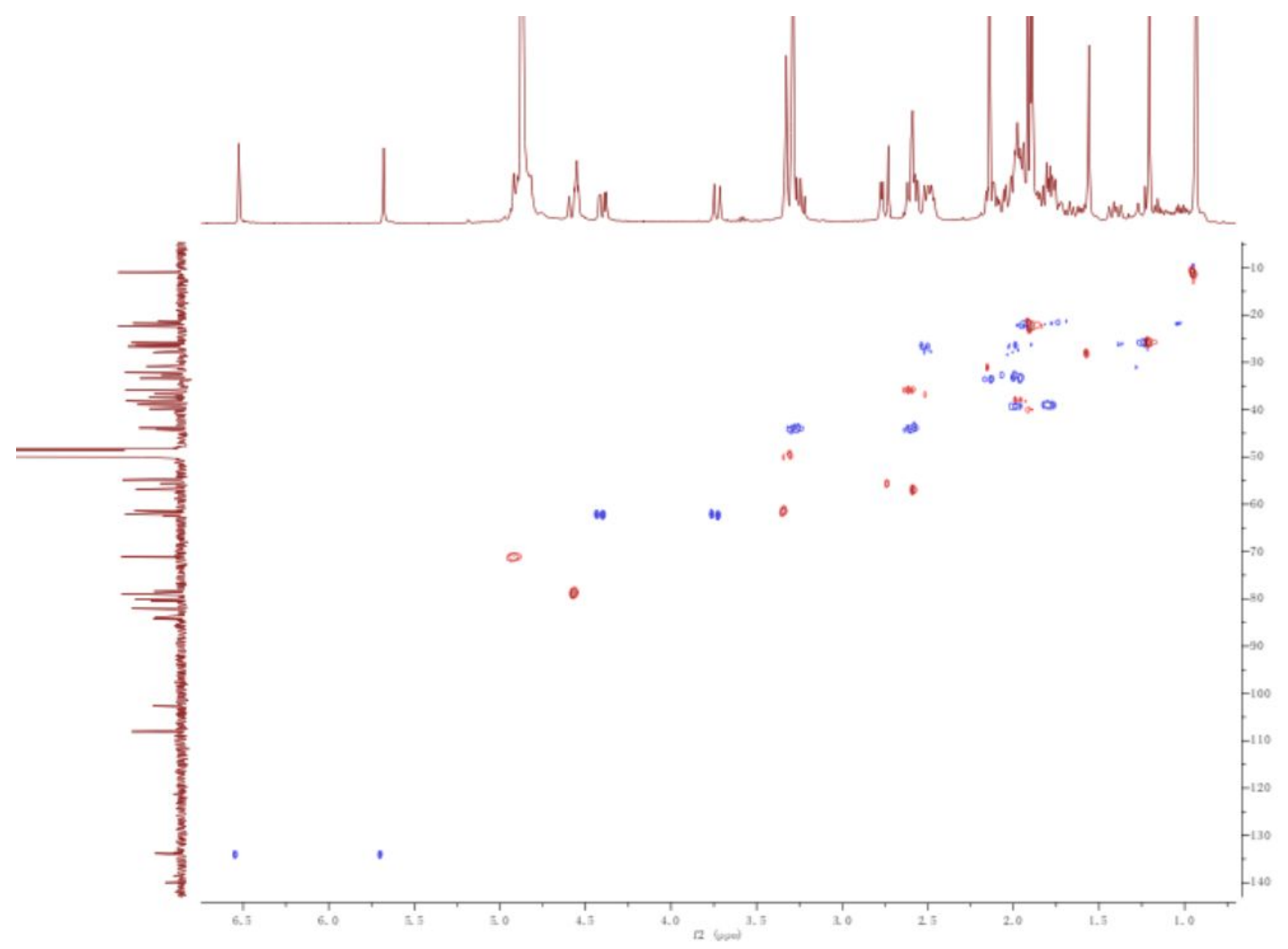

Figure S21. HSQC spectrum $(400 \mathrm{MHz})$ of $\mathbf{4 + 5}$ in $\mathrm{CD}_{3} \mathrm{OD}$ 


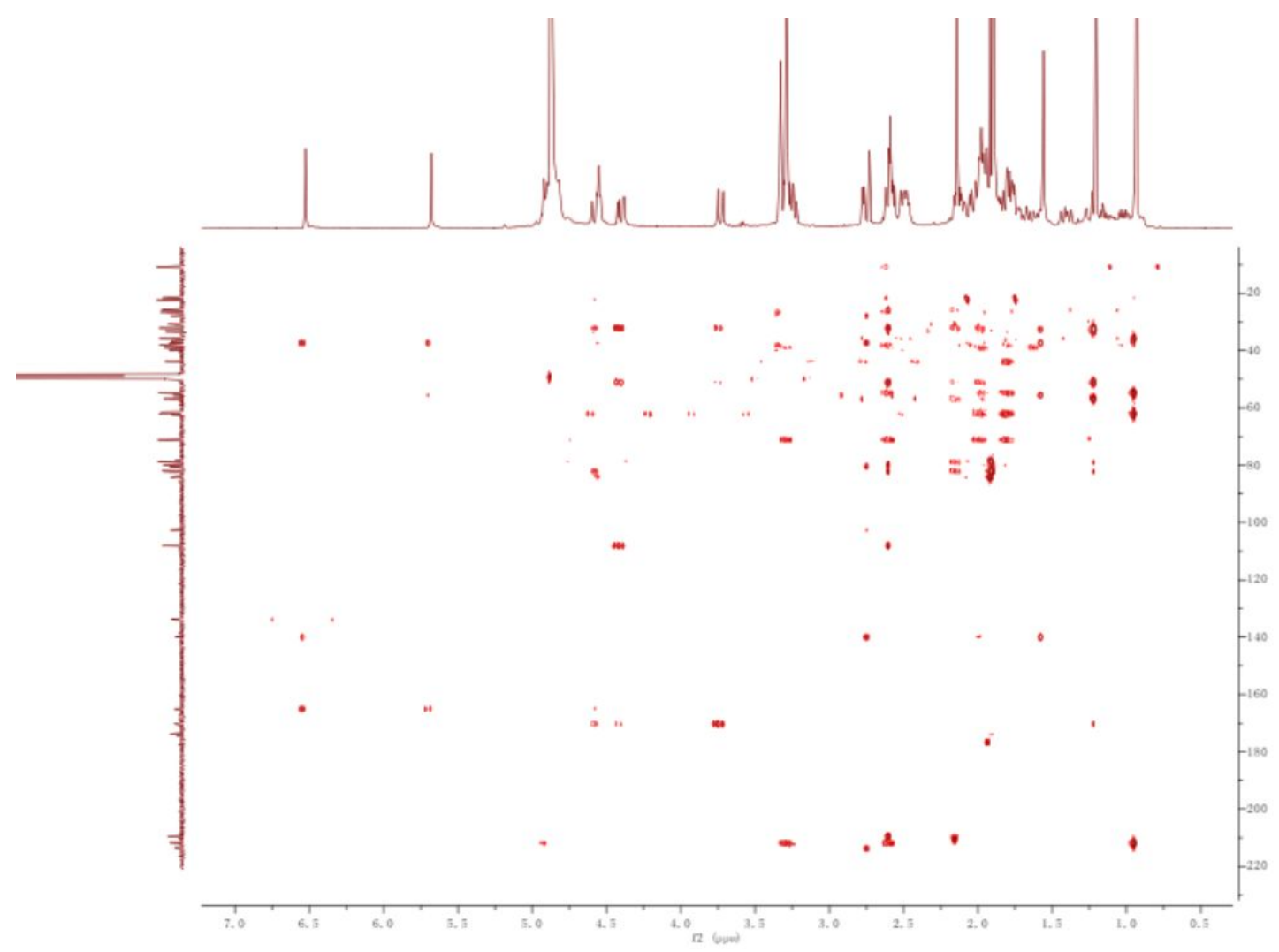

Figure S22. $\mathrm{HMBC}$ spectrum $(400 \mathrm{MHz})$ of $\mathbf{4}+\mathbf{5}$ in $\mathrm{CD}_{3} \mathrm{OD}$

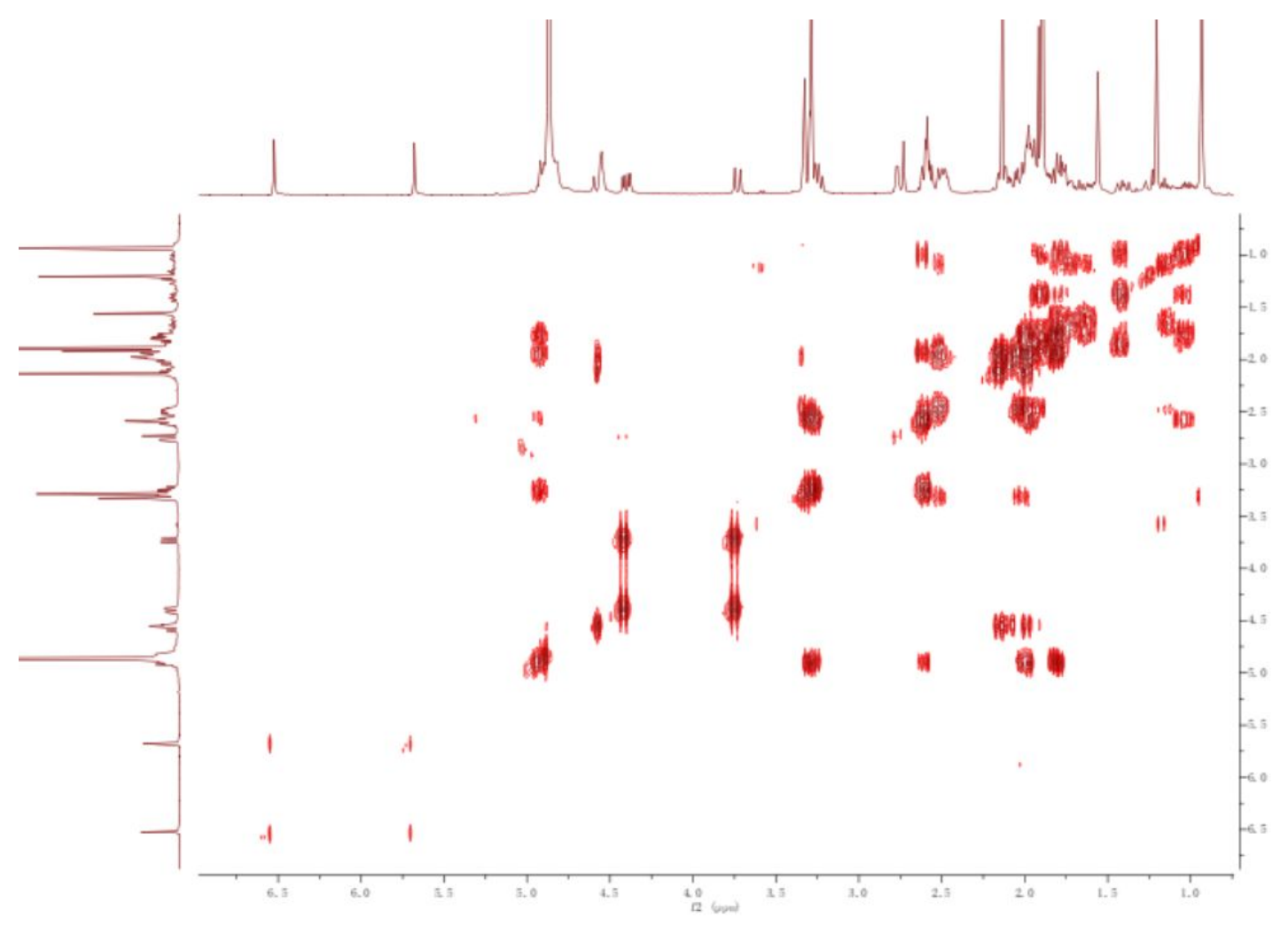

Figure S23. ${ }^{1} \mathrm{H}-{ }^{1} \mathrm{H}$ COSY spectrum $(400 \mathrm{MHz})$ of $\mathbf{4 + 5}$ in $\mathrm{CD}_{3} \mathrm{OD}$ 


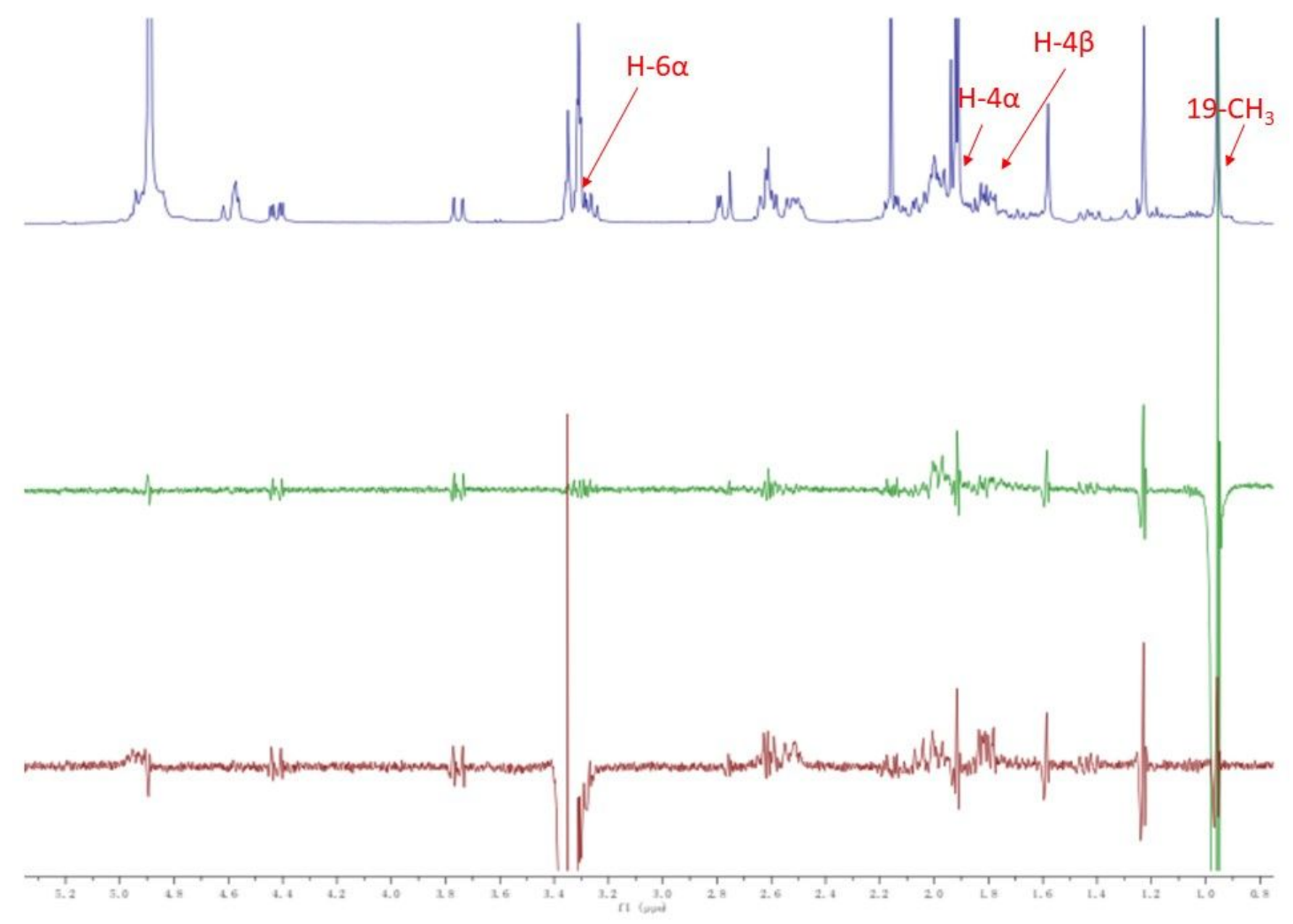

Figure S24. 1D NOESY spectrum $(400 \mathrm{MHz})$ of $\mathbf{4 + 5}$ in $\mathrm{CD}_{3} \mathrm{OD}$

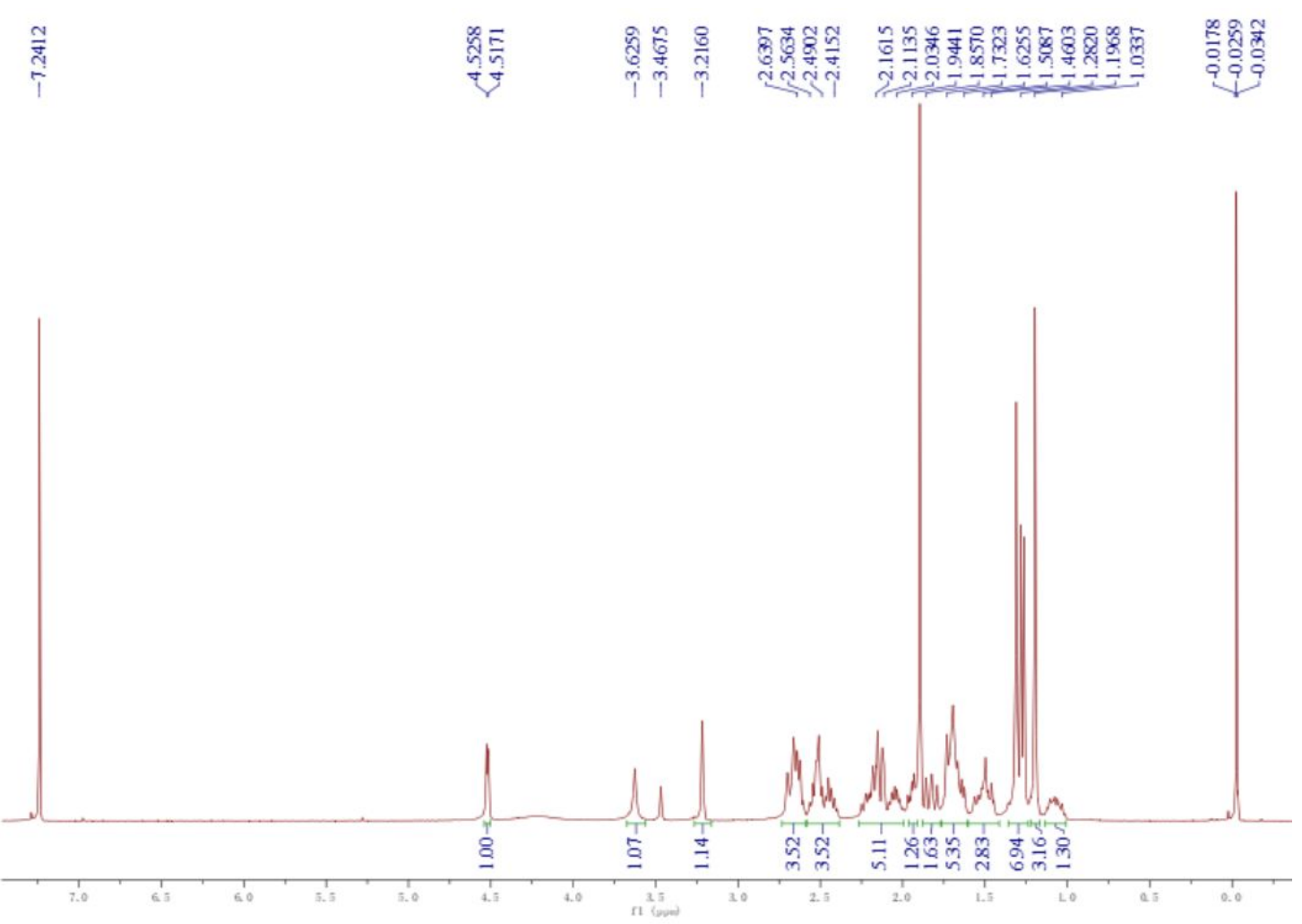

Figure S25. ${ }^{1} \mathrm{H}$ NMR spectrum $(400 \mathrm{MHz})$ of 13 in $\mathrm{CDCl}_{3}$ 


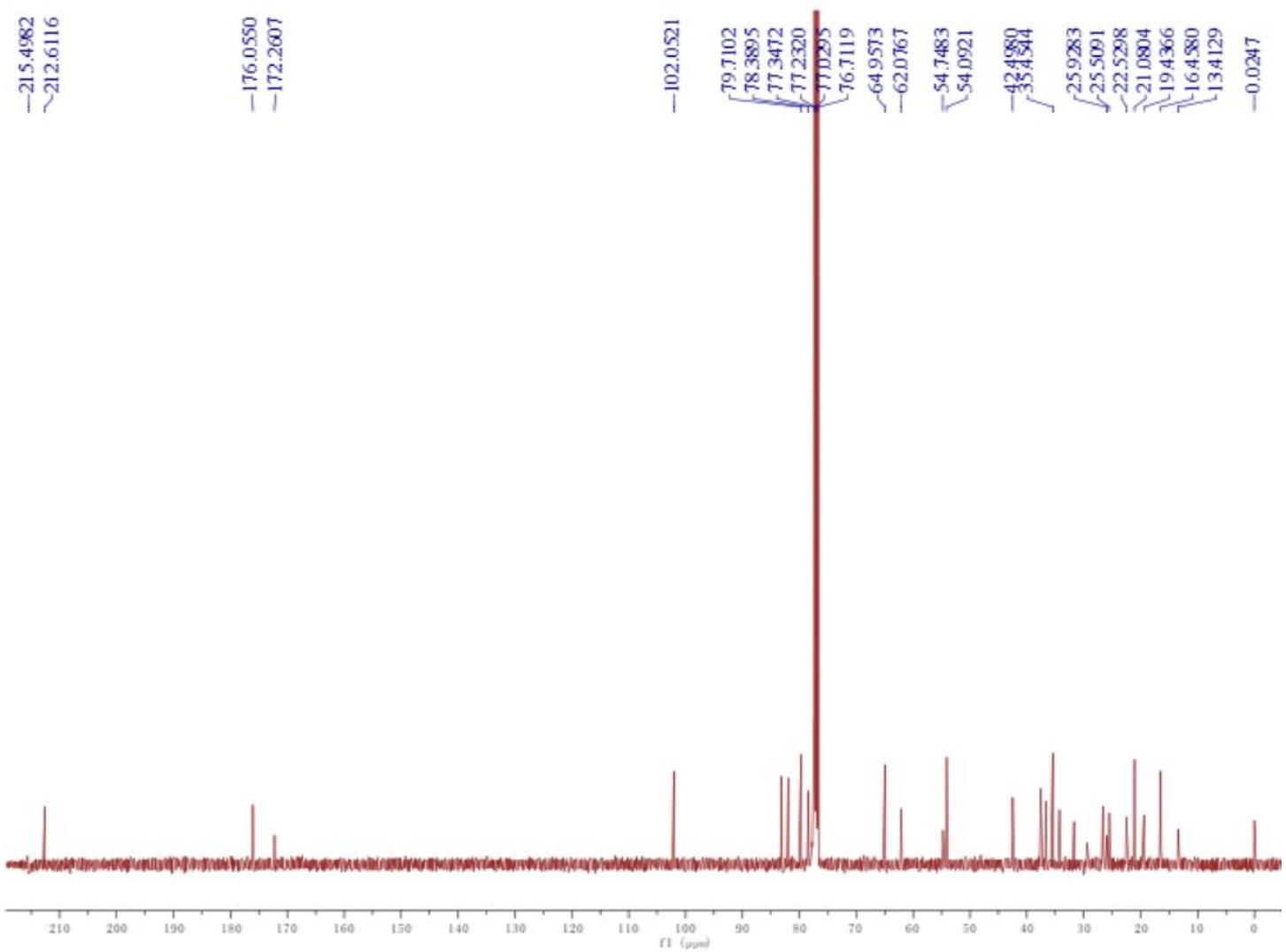

Figure S26. ${ }^{13} \mathrm{C}$ NMR spectrum $(100 \mathrm{MHz})$ of 13 in $\mathrm{CDCl}_{3}$



Figure S27. HSQC spectrum (400 MHz) of 13 in $\mathrm{CDCl}_{3}$ 


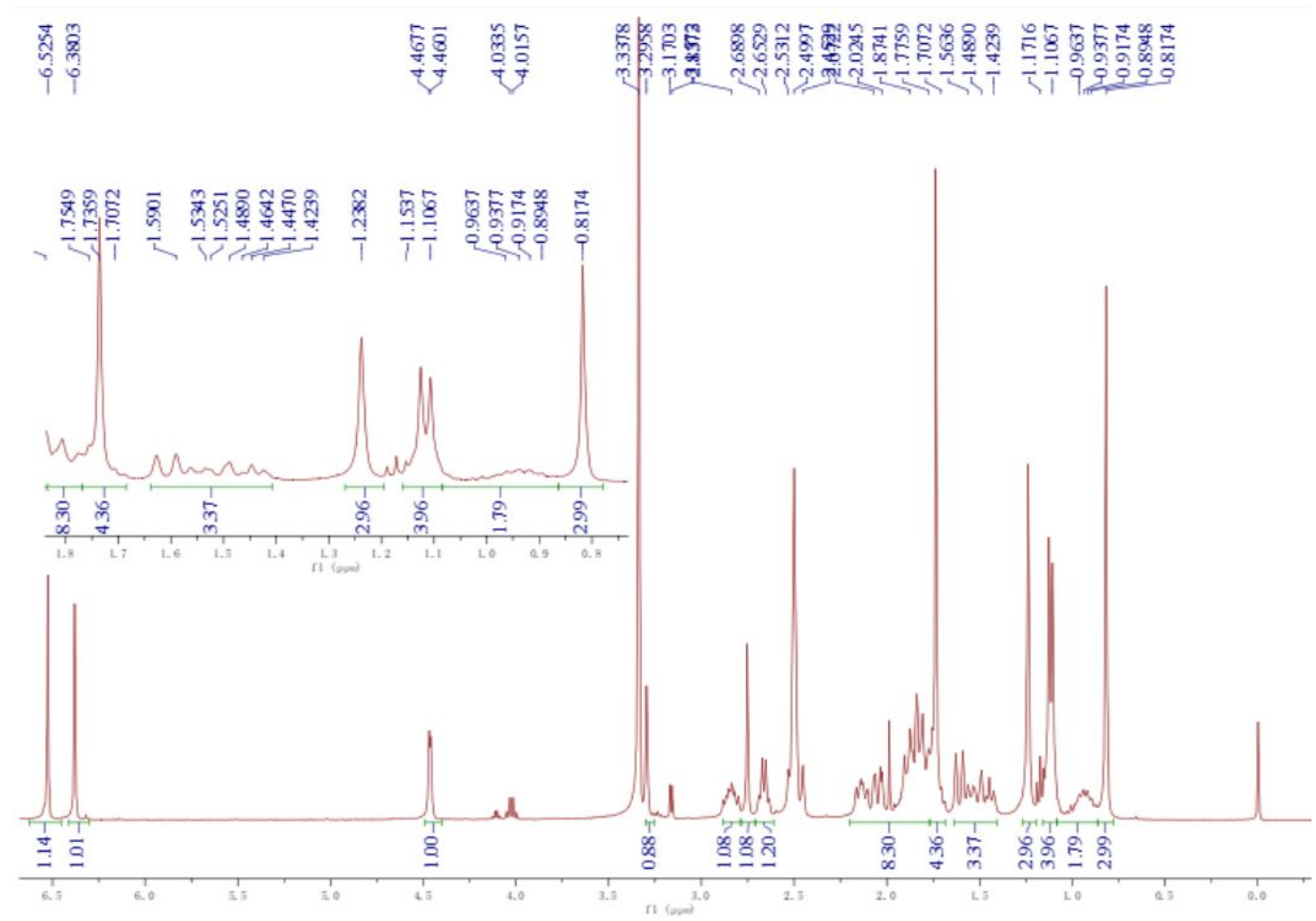

Figure S28. ${ }^{1} \mathrm{H}$ NMR spectrum $(400 \mathrm{MHz})$ of 13a in DMSO- $d_{6}$

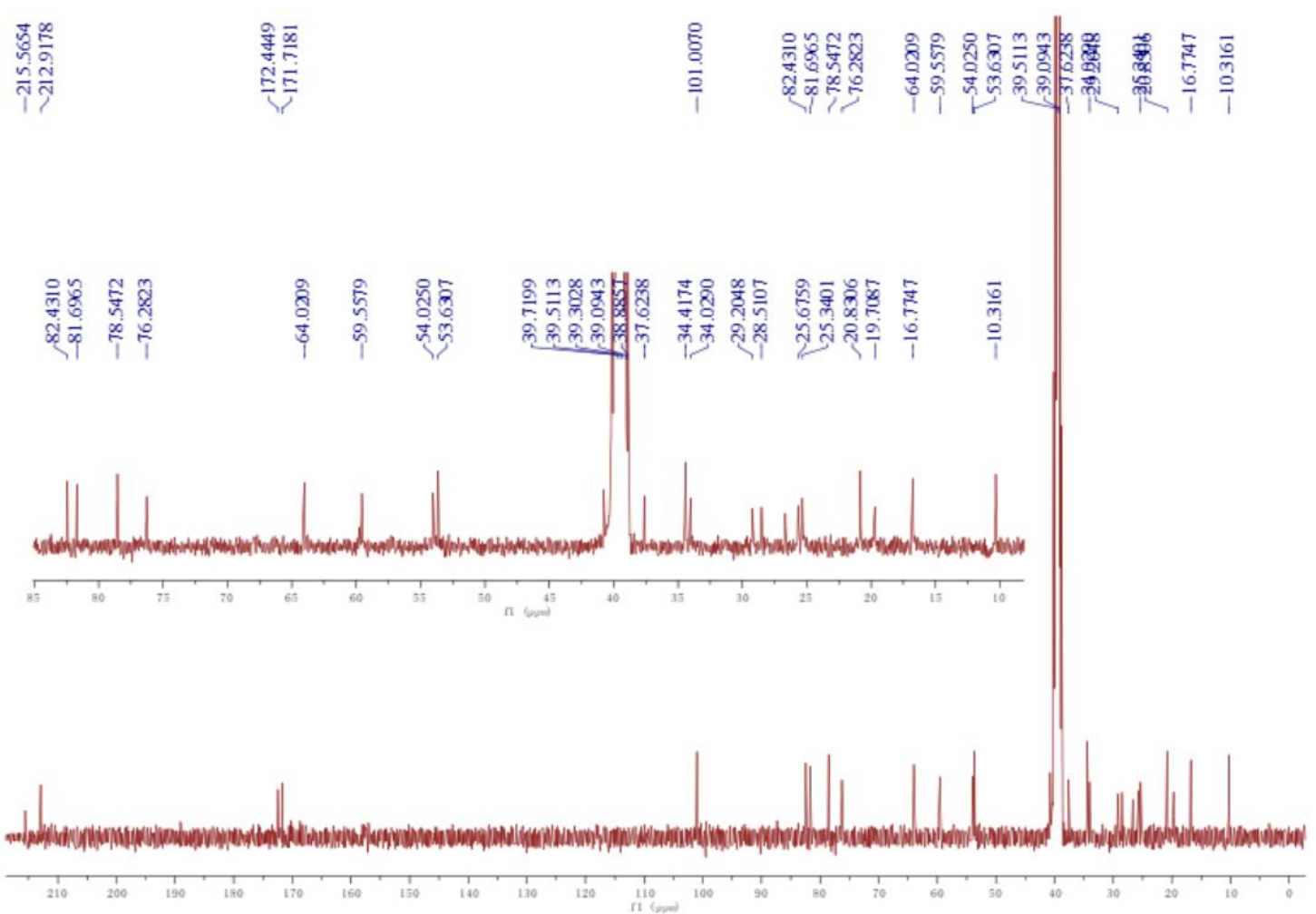

Figure S29. ${ }^{13} \mathrm{C}$ NMR spectrum $(100 \mathrm{MHz})$ of 13a in DMSO- $d_{6}$ 


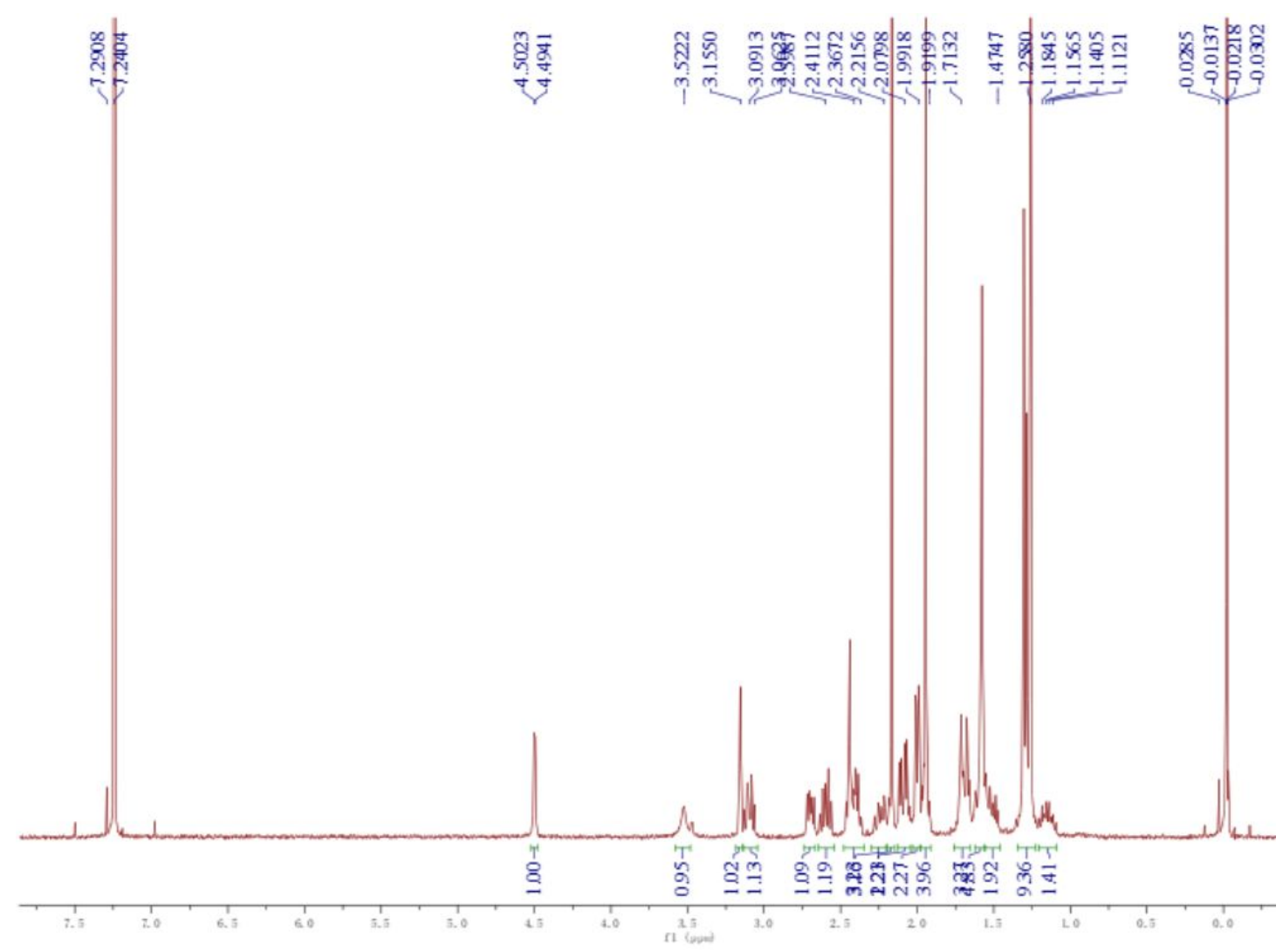

Figure S30. ${ }^{1} \mathrm{H}$ NMR spectrum $(400 \mathrm{MHz})$ of $\mathbf{1 3 a}$ in $\mathrm{CDCl}_{3}$

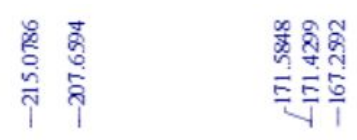

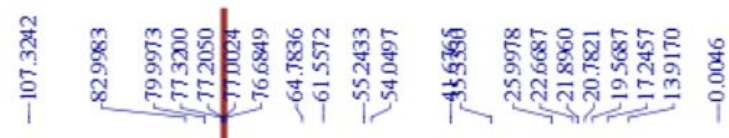

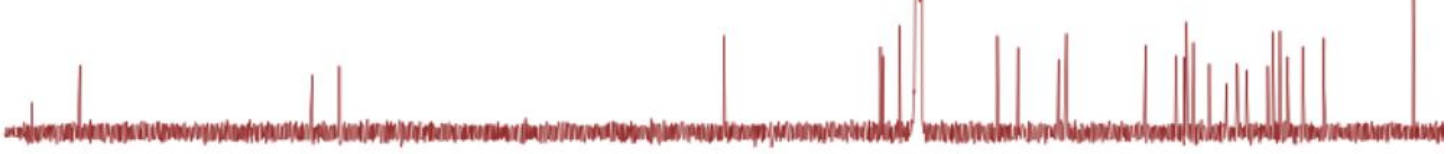

Figure S31. ${ }^{13} \mathrm{C}$ NMR spectrum $(100 \mathrm{MHz})$ of $\mathbf{1 3 a}$ in $\mathrm{CDCl}_{3}$ 


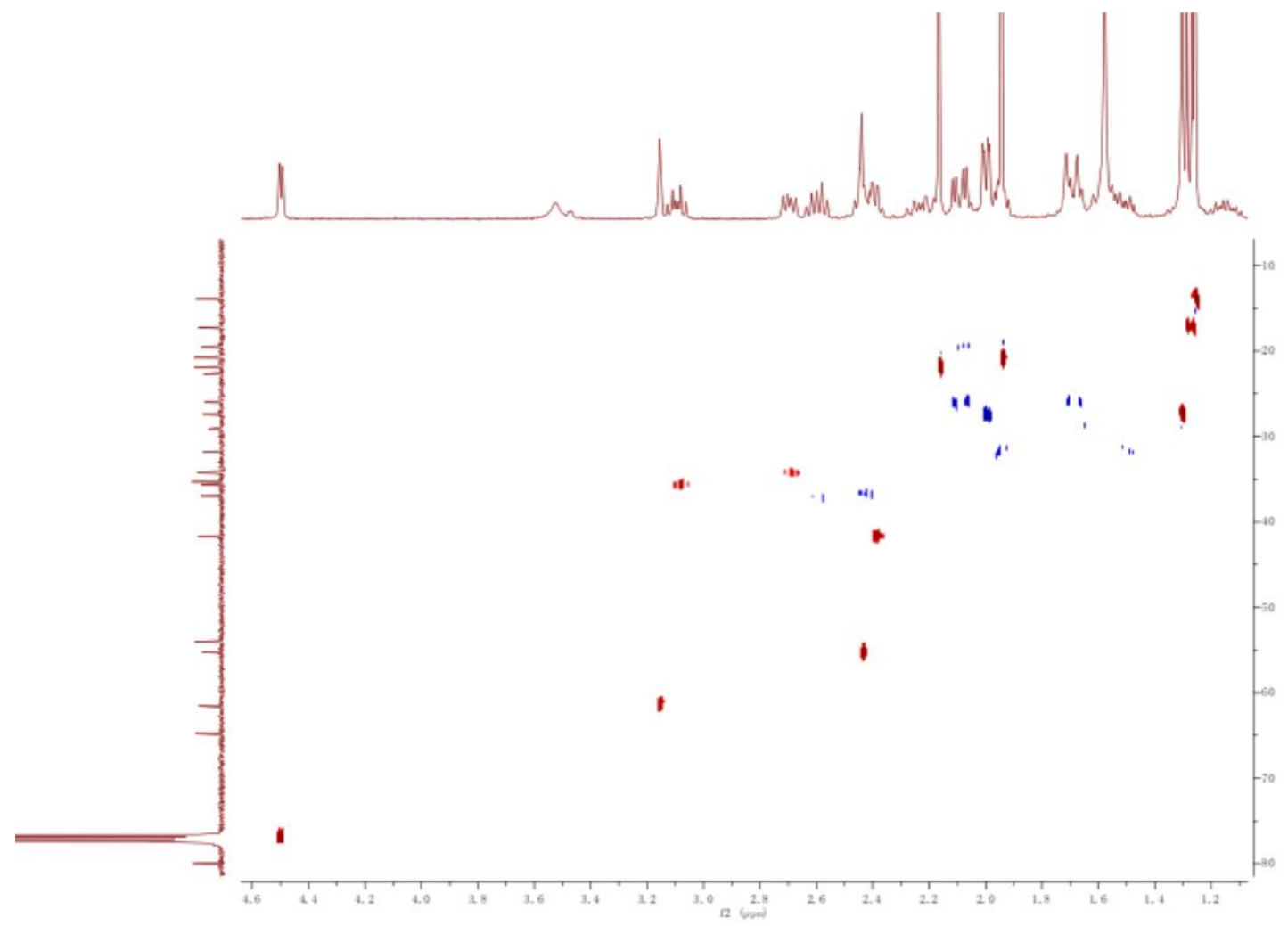

Figure S32. HSQC spectrum (400 MHz) of 13a in $\mathrm{CDCl}_{3}$ 


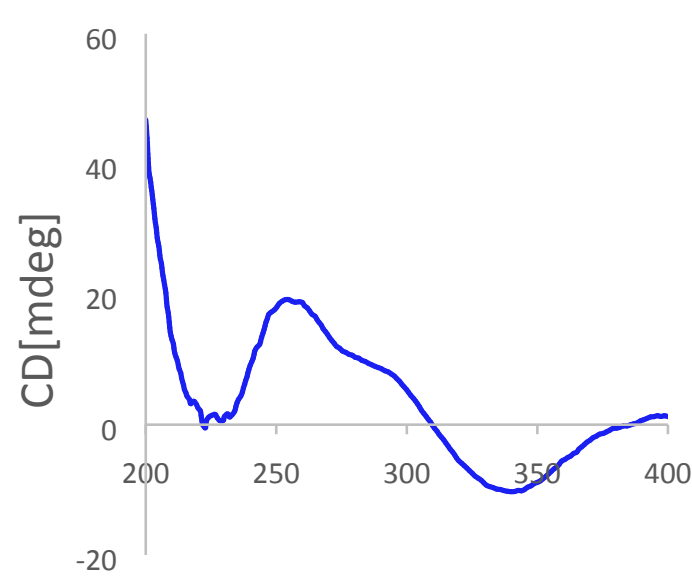

1

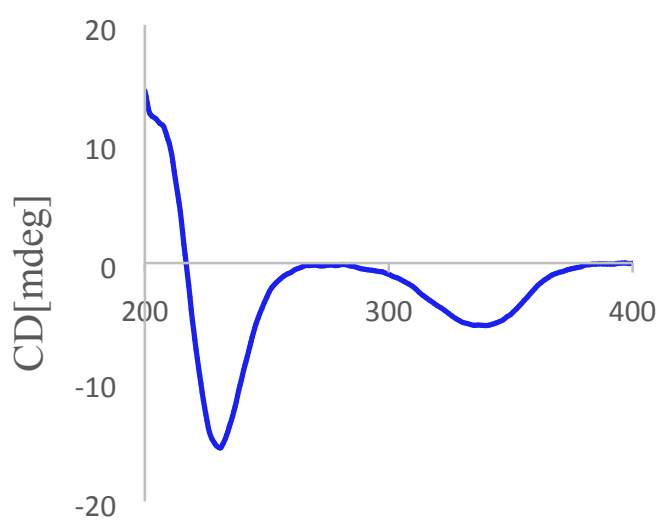

3

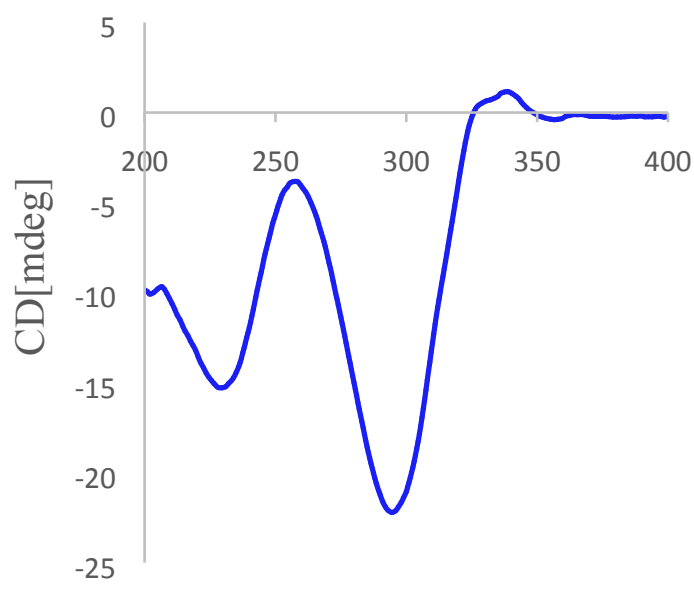

13

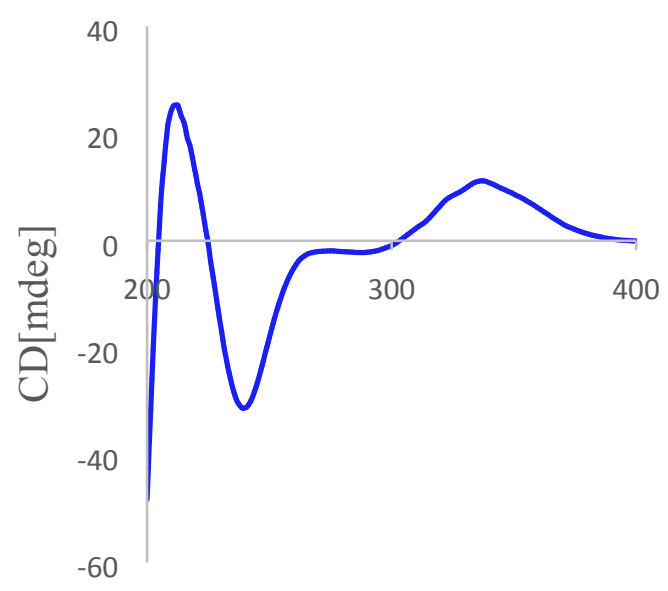

2

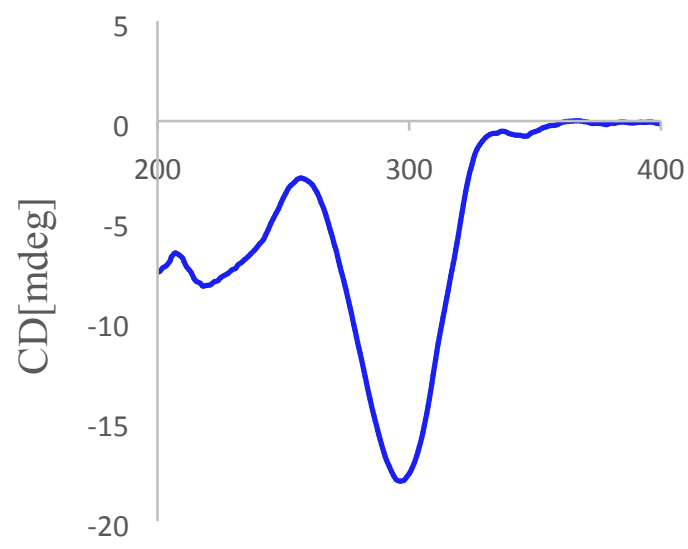

$4+5$

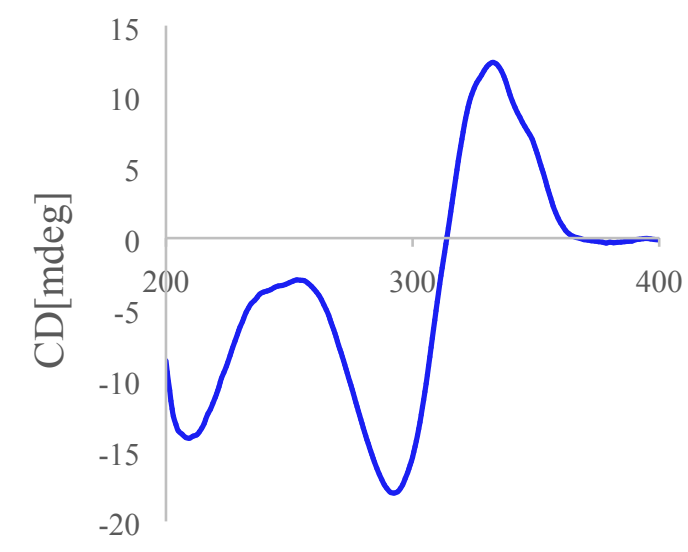

$13 a$

Figure S33. ECD spectra of 1-5 and their derivatives 13, and 13a. 